\title{
Eocene (Duchesnean and earliest Chadronian) brontotheres (Brontotheriidae), Protitanops curryi and cf. Parvicornus occidentalis, from West Texas and Mexico
}

\author{
Matthew C. Mihlbachler and Donald R. Prothero
}

\begin{abstract}
Large horned brontotheres (Brontotheriidae) are abundantly represented in Duchesnean and early Chadronian mammal faunas from the Big Bend Area of West Texas and nearby Mexico. The majority of this material, which until now has never been fully examined, is identified and described. The first brontothere to be named from this region, Menodus bakeri Stovall, 1948, is found to be a nomen dubium. The majority of the fossil material is referrable to Protitanops curryi Stock, 1936. P. curryi, previously only known from a single specimen from the Titus Valley Formation of Southern California, is now recognized in both the Duchesnean and Chadronian land mammal ages of Texas. It occurs in the late Duchesnean Porvenir Local Fauna from the lower part of the Chambers Tuff Formation and from the early Chadronian Little Egypt local fauna from the upper part of the Chambers Tuff Formation and the lower Chisos Formation in the Big Bend National Park Texas. A single specimen from the early Chadronian Rancho Gaitan local fauna of the Prietos Formation of Mexico is also identified as $P$. curryi. The extensive Protitanops curryi material from Texas and Mexico broadens the biostratigraphic and geographic ranges of this species and provides a more extensive understanding of its morphology and phylogenetic position. Duchesneodus uintensis (Peterson, 1931) has been previously identified with diagnostic material in the Blue Cliff horizon of the lower Chambers Tuff. Duchesneodus was previously identified in the early Duchesnean Skyline Channels of the Devil's Graveyard Formation, but this material is better identified as cf. Parvicornus occidentalis Mihlbachler and Deméré, 2009. D. uintensis is therefore restricted to the late Duchesnean in Texas.
\end{abstract}

Matthew C. Mihlbachler. Department of Anatomy, New York Institute of Technology College of Osteopathic Medicine, Old Westbury, New York 11658, USA. mmihlbac@nyit.edu

Donald R. Prothero, Department of Vertebrate Paleontology, Natural History Museum of L.A. County, 900 Exposition Blvd., Los Angeles, California 90007, USA. donaldprothero@att.net

Mihlbachler, Matthew C. and Prothero, Donald R. 2021. Eocene (Duchesnean and earliest Chadronian) brontotheres (Brontotheriidae), Protitanops curryi and cf. Parvicornus occidentalis, from West Texas and Mexico. Palaeontologia Electronica, 24(3):a35. https://doi.org/10.26879/944

palaeo-electronica.org/content/2021/3479-texas-brontotheriidae

Copyright: November 2021 Society of Vertebrate Paleontology.

This is an open access article distributed under the terms of the Creative Commons Attribution License, which permits unrestricted use, distribution, and reproduction in any medium, provided the original author and source are credited.

creativecommons.org/licenses/by/4.0 
Keywords: Brontotheriidae; Duchesnean-Chadronian boundary; Chisos Formation; Chambers Tuff Formation; Devil's Graveyard Formation; Prietos Formation; Texas; Mexico

Submission: 16 November 2018. Acceptance: 18 October 2021.

\section{INTRODUCTION}

Brontotheres (Brontotheriidae) were the dominant land megaherbivores of the middle and late Eocene of North America and Asia. The infratribe Brontotheriita, which ranged over North America and, to a lesser extent, Asia, evolved large body sizes, heavily built skeletons, massive saddle shaped skulls, enlarged frontonasal appendages (horns), thickened zygomatic arches, and reduced anterior dentitions (Mihlbachler, 2008). The genus Megacerops (sensu Mihlbachler et al., 2004) is the terminal genus of infratribe Brontotheriita, the last North American brontothere. It is one of the best represented megaherbivores in the North American mammal record. The evolution and paleobiology of Megacerops and closely allied species are potentially rich areas of investigation, although ambiguity regarding the basic systematics of this group is an obstacle to further research (Prothero and Schoch, 2002).

The large horned brontotheres of the late Eocene (Chadronian land mammal age) were initially thought to be speciose but for specious reasons. Copious amounts of fossils, now referred to the genus Megacerops, were collected by early paleontologists Cope, Marsh, and Hatcher from the White River Group of ancient Wyoming, the Dakotas, and Nebraska (Osborn, 1929; Scott and Jepsen, 1941) and Cypress Hills, Saskatchewan (Russell, 1940; Tokaryk, 1985) often with erroneous stratigraphic associations (Clark, 1937; Prothero and Schoch, 2002). The abundance of material lulled early researchers into overestimating the diversity contained within these fossil assemblages, and they erected a plentitude of species and genera (e.g., Brontops, Diploclonus, Allops, Menodus, Megacerops, Brontotherium et al.) based on horn and dental variations. In hindsight, these variations are to a great extent explained by sexual dimorphism and other forms of intraspecific variation that are now known to have been common in large perissodactyls (Coombs, 1975; Mihlbachler et al., 2004; Mihlbachler, 2005, 2007a, 2011). Scott and Jepsen (1941) recognized this taxonomic quandary, and considered the hopeless mix of species, specimens, and erroneous stratigraphic interpretations of brontotheres from the
White River to be an "insoluble problem". Subsequent genus-level revisions have suggested that late Eocene brontotheres from the White River consists of three genera (Mader, 1989, 1998), but all of the brontothere material collected from the White River and Cypress Hills regions have also been interpreted as having belonged to one species (Clark, 1937). Mihlbachler et al. (2004) suggested there are two readily diagnosible species, Megacerops coloradensis Leidy, 1870, a species with unforked horns, and $M$. kuwagatarhinus Mader and Alexander, 1995, a rarer species with distally bifurcated horns.

Although the true biodiversity of this group remains enigmatic, the species diversity of late Eocene brontotheres is undeniably depauperate compared to the last comprehensive systematic survey of the group in which 38 species were recognized from the upper Eocene White River and Cypress Hills deposits (Osborn, 1929). Nonetheless, subsequent discoveries of other species of Brontotheriita from middle and late Eocene deposits of other geographic regions in both North America and Asia has revealed a geographically broader radiation of species belonging to the infratribe Brontotheriita and closely allied to the classic taxon, Megacerops. There are presently nine recognized species of Brontotheriita known to have ranged through the Uintan, Duchesnean, and Chadronian land mammal ages in North America and contemporaneous times in Asia (Mihlbachler et al., 2004; Mihlbachler, 2007b, 2008; Mihlbachler and Deméré, 2009). In addition to Megacerops coloradensis and $M$. kuwagatarhinus, species known from North America include Protitanops curryi Stock, 1936 from the Titus Canyon Formation of Southern California, Notiotitanops mississippiensis Gazin and Sullivan, 1942 from the Archusa Marl Member of the Cook Mountain Formation in Mississippi, Duchesneodus uintensis (Peterson, 1931) from the Duchesne River Formation of Utah, Galisteo Formation of New Mexico, and Vieja Area of Texas (Lucas and Schoch, 1989; Mihlbachler, 2008), Eubrontotherium clarnoensis Mihlbachler, 2007b from the Clarno Formation of Oregon, and Parvicornus occidentalis Mihlbachler and Deméré, 2009 from the Santiago Formation of Southern California. Two additional species are known exclu- 

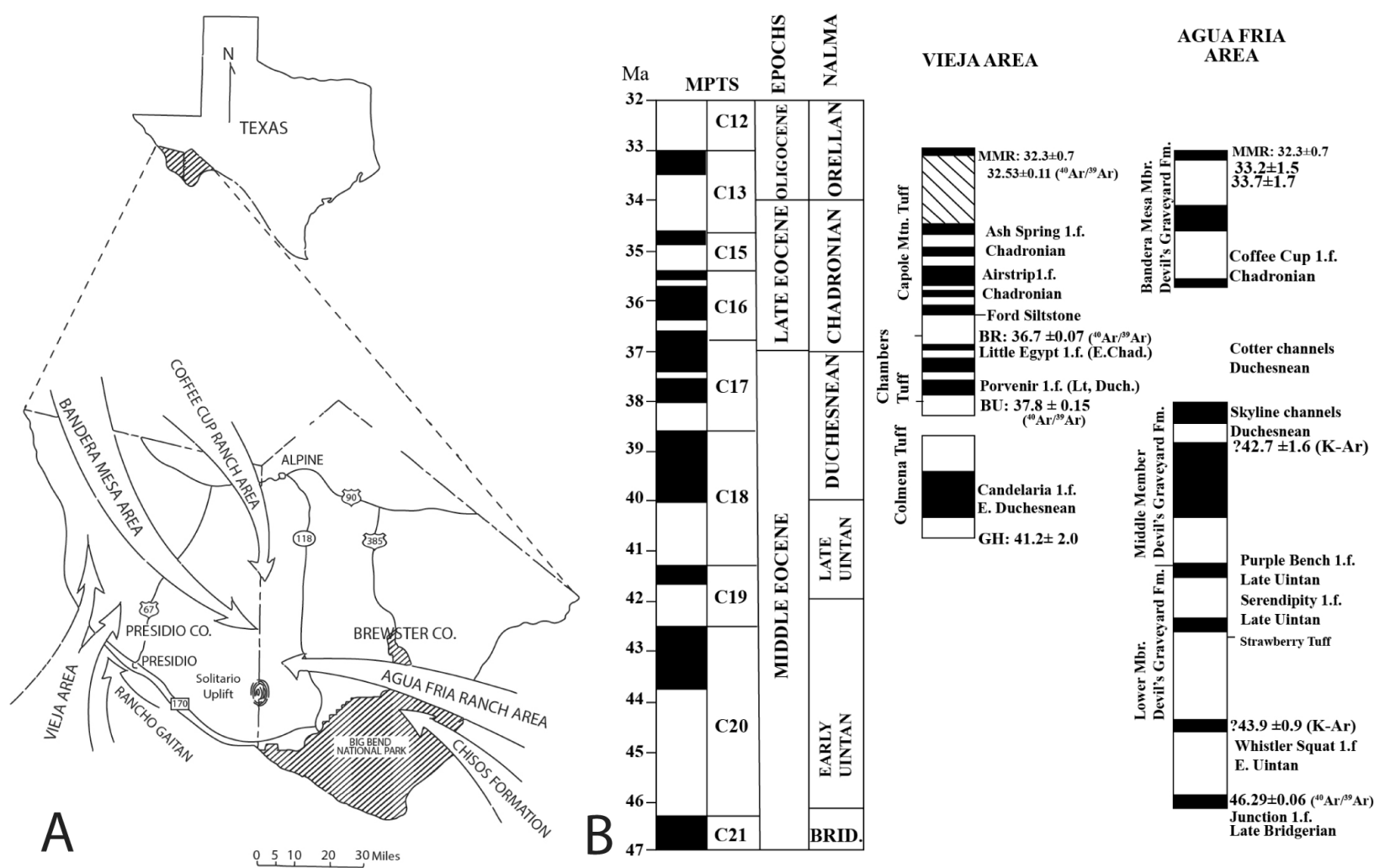

FIGURE 1. Index map of collection areas (left) and correlation and dating (right) of the major mammal fossil localities of the Eocene of Trans-Pecos Texas. Magnetic stratigraphy of Testarmata and Gose (1979), Walton (1992), and Prothero (1996) and its correlation with the global magnetic polarity time scale. Location of the important mammalian local faunas (I.f.) and volcanic ash dates are shown. Diagonal cross-hachured pattern denotes sections of indeterminate polarity. Normal polarity is in black, reversed polarity is in white. Abbreviations: BRID. = Bridgerian; $\mathrm{BR}=\mathrm{Bracks}$ Rhyolite; BU = Buckshot Ignimbrite; GB = Gill Breccia; MMR = Mitchell Mesa Rhyolite; MPTS = magnetic polarity; NALMA = North American land mammal age. (map after Wilson, 1978; correlation after Prothero, 1996).

sively from Asia: Parabrontops gobiensis (Osborn, 1925) from the Urtyn Obo Formation of Nei Mongol, and Dianotitan lunanensis (Chow and $\mathrm{Hu}$, 1959) from the Lumeiyi Formation of Yunnan China (Chow et al., 1974; Russell and Zhai, 1987). Specimens from late Eocene Ergilin Dzo of Mongolia are also referred to Eubrontotherium clarnoensis (Mihlbachler, 2008). An abundance of mostly undescribed brontothere fossil material occurs in Duchesnean and early Chadronian age rocks the from West Texas and nearby Ojinaga area of Mexico. In this paper, specimens are referred to Protitanops curryi and cf. Parvicornus occidentalis, species that were previously unrecognized in this region.

\section{STRATIGRAPHY AND LOCALITIES}

Numerous geochronological studies on the Trans-Pecos Texas Eocene-Oligoce strata have been undertaken by Testarmata and Gose (1979), Walton (1992), and Prothero (1996), summarized in Prothero (1996). These correlations are shown in Figure 1, and discussed further below.

The earliest brontothere from this region is from the Uintan lower member of the Devil's Graveyard Formation in the Aqua Fria Area of Brewster County (Whistler Squat and Serendipity local faunas). The Whistler Squat I.f. occurs beneath a K-Ar date of $43.9 \pm 0.9 \mathrm{Ma}$, and is in reversed Chron C20R, so it is about $45 \mathrm{Ma}$ in age, or early Uintan in age. The Serendipity I.f. occurs in beds which correlate with Chron C19r (about 42 $\mathrm{Ma}$, and yields a fauna that is late Uintan in age (Prothero, 1996). This brontothere was originally described as Sthenodectes australis Wilson, 1977a but it is now considered a junior synonym of Protitanotherium emarginatum Hatcher, 1895 (Mihlbachler, 2008). P. emarginatum is an early horned brontothere that is basal to Brontotheriita. This fossil material has previously been identified and described (Mihlbachler 2008) and is not further considered here. 
Brontothere fossils are also known from the Skyline Channels of the Devil's Graveyard Formation of the Aqua Fria-Green Valley area of Brewster County, Texas. The Skyline channels yield a Duchesnean fauna, are correlated with magnetic Chron C17r (38-39 Ma) according to Prothero (1996). These fossils were previously described as "?Duchesneodus cf. uintensis" by Wilson and Stevens (1986) and Duchesneodus uintensis by Lucas and Schoch (1989) have unclear species identities due to their incomplete nature (Mihlbachler, 2008), but they are now more appropriately referred to below as cf. Parvicornus occidentalis.

Two brontothere species have been identified from the late Duchesnean and early Chadronian Chambers Tuff Formation in the Vieja-Ojinaga area of Presidio County, Texas. The lower part of the Chambers tuff yields the late Duchesnean Porvenir I.f., which lies above the Buckshot Ignimbrite, which is ${ }^{40} \mathrm{Ar} / 39 \mathrm{Ar}$ dated at $37.8 \pm 0.15 \mathrm{Ma}$, and correlates with Chron C17n (about 37-38 Ma) (Prothero, 1996). Duchesneodus uintensis is represented by diagnostic fossil material in the Blue Cliff Horizon of the lower part of the Chambers Tuff, including a remarkably preserved skull (FMNH PM 136) (Mihlbachler, 2008; figures 159-161). This species needs no further consideration here. Menodus bakeri (Stovall, 1948) was described from the first brontothere material collected from this region in 1940 in what is now considered the lower part of the Chambers Tuff Formation. Large collections of brontothere material have since been acquired by the TMM and FMNH from the Chambers Tuff Formation and nearby Chisos Formation (Wilson, 1977a). These collections represent a horned brontothere that is larger than Duchesneodus uintensis and lacks its distinct parietal dome. This species likely belongs to the same species as the holotype mandible (OU 18-4-S17) of Menodus bakeri but due to the fragmentary nature of the holotype, Menodus bakeri is here considered a nomen dubium, and the more complete fossil material since collected from these areas is referred to below as Protitanops curryi.

Stratigraphically higher in the Chambers tuff section is the Little Egypt I.f., which produces an earliest Chadronian fauna. It lies beneath the Bracks Rhyolite, which is ${ }^{40} \mathrm{Ar} / 39 \mathrm{Ar}$ dated at $36.7 \pm$ $0.07 \mathrm{Ma}$, and paleomagnetically correlated with the later part Chron C17n (around 36.5-37.5 Ma) (Prothero, 1996). Based on the analysis below, Protitanops curryi occurs in both late Duchesnean and early Chadronian deposits from the Porvenir and Little Egypt local faunas from Chambers Tuff of the Vieja-Ojinaga area, and from the Lower Chisos Formation in the Big Bend National Park Group in Brewster County (Wilson, 1977a, b; Schiebout et al., 1987).

A large amount of fossil material referable to Protitanops curryi has been recovered from the Chisos Formation in Big Bend National Park, Brewster County, Texas (Wilson, 1977a). The majority of this material was recovered from what is apparently a brontothere quarry site with numerous articulated or semi-articulated specimens found along an outcrop of tuffaceous material a few feet below igneous rock and adjacent to coarse bed load channel in the Chisos Formation (Wann Langston Papers, Series II: Field Notes 1936-1999 in the archives of the TMM). Several major Eocene and Oligocene basalts are known in the region (Turner et al., 2011; Maxwell, 1967) although the lateral extent of the sediments producing the fossils, and their relationship to dated strata are not known.

Finally, a skull previously referred to ?Brontops cf. brachycephalus (Ferrusquía-Villifranca, 1967; Ferrusquía-Villafranca, 1984) from the nearby Prietos Formation, Ojinaga-Chihuahua area of Mexico, Rancho Gaitan local fauna, is also referred to Protitanops curryi. The Rancho Gaitain I.f. has never been studied for paleomagnetic correlation or dated radiometrically, but based on its earliest Chadronian fauna, it is correlated with magnetic Chron C16r, and dated between 36.537.0 Ma (Prothero and Emry, 2004).

This newly identified $P$. curryi material significantly amplifies knowledge on the morphology, phylogenetic position, and temporal and spatial distribution of this species, which was previously known from a single specimen (LACM/CIT 1854) from the early Chadronian Titus Canyon Formation of Southern California. This newly referred material establishes the occurrence of $P$. curryi in both the Duchesnean and Chadronian land mammal ages.

\section{MATERIALS AND METHODS}

The methods for identification of fossil specimens, species diagnosis, and phylogenetic analysis are described in related studies of the systematics of Brontotheriidae (Mihlbachler, 2008). Craniodental terminology and methods for measurements follow Mihlbachler (2008) and Mihlbachler and Deméré (2009). To delimit species, a modified form of population aggregation analysis (Sites and Marshall, 2004) was used where quarry samples and other stratigraphically constrained assemblages of other brontothere species constrain expectations about intraspecific variation. 
Important referent assemblages for Brontotheriita include Duchesneodus uintensis from the Duchesneodus quarry from the LaPoint Member of the Duchesne River Formation in Duchesne County, Utah (Scott, 1945; Lucas and Schoch, 1989; Mihlbachler, 2008), an undescribed assemblage of cf. Megacerops coloradensis from the Trigonias rhino quarry in the Chadron Formation of Weld County, Colorado (Gregory and Cook, 1928), Eubrontotherium clarnoensis from the Hancock Quarry of the Clarno Formation, Wasco County, Oregon (Mihlbachler, 2007b), and Parvicornus occidentalis from stratigraphically associated localities in the Santiago Formation of San Diego County, California (Mihlbachler and Deméré, 2009). Size comparisons with other species were made with data and summary statistics published in Mihlbachler (2007b; 2008) and Mihlbachler and Deméré (2009).

In light of these newly identified fossil materials and additional character information that is now available for Protitanops curryi, a phylogenetic analysis of Brontotheriidae is reported. This analysis is based on 242 character states distributed among 94 characters and coded for 59 species including two outgroups, "Hyracotherium" (=Xenicohippus osborni sensu Froehlich, 2002), Pachynolophus livinierensis Savage et al., 1965, early brontotheriioids Danjiangia pingi Wang, 1995, and Lambdotherium popoagicum Cope, 1880 (Appendix 1). The present dataset is derived from Mihlbachler and Samuels (2016) with additional newly described species, Maobrontops paganus Averianov et al., 2018 and Epimanteoceras mae Li, 2018. The dataset includes all taxa belonging to Brontotheriidae that produce unique combinations of character data. All brontotheres were included as species except Palaeosyops due to uncertainty about the species-level taxonomy of this genus (Gunnell and Yarborough, 2000; Mihlbachler, 2008; Mader, 2009). Data for 15 characters $(5,30,71$, 72, 74-82, 88, 94), previously missing for Protitanops curryi, were entered based upon the newly described material. Additional ambiguities in character states regarding variation in canine size (89) and horn morphology (90) for $P$. curryi have been settled by the additional specimens.

Characters 1-92 are described in previous publications (Mihlbachler, 2008, 2011; Mihlbachler and Samuels, 2016). Two additional characters $(93,94)$ are described here.
Character 93. Cusp (or cusp-like eminence) on the antero-lingual cingula of upper premolars: (0) not present, (1) present in some individuals.

In Duchesneodus uintensis a distinct cusp-like eminence on the anterior cingulum of premolars (P2-P4) is present on some specimens referred to this species. When present, this cusp is largest and most distinct on the posterior-most premolar (P4) (Mihlbachler, 2008). A similar trait can be observed on some specimens of Megacerops coloradensis and $M$. kuwagatarhinus. In these species, this trait is variably present, and therefore larger samples may lead to the discovery of this trait in poorly represented taxa. Averianov et al. (2018) described and figured similar cusp-like eminences on the anterior cingulum of P4 in Maobrontops paganus.

\section{Character 94. Lower incisor size and morphology $(0)$ ranging from spatulate to subcaniniform (appearing to be functional incisors), (1) short, reduced in size, wedge shaped or globular (appearing to be vestigial).}

In this analysis, multistate character 73 has been split into two characters (characters 73 and 94). Many brontotheriioid lower incisors vary gradationally from a thin spatulate crown morphology to a rounder, thicker subcaniniform crown morphology. These states are now represented by character 73. Members of Brontotheriita have incisors with an almost vestigial appearance; they are very small with a bland wedge-shaped or globular morphology. Previously character 73 included all of these incisor morphology conditions, although the sum total of these conditions do not form a logically ordered morphological gradation from one morphological extreme to another. It is not clear if the reduced incisor condition is derived from a more incisiform or subcaniniform condition. With the last of these conditions removed from character 73, that character can more logically be treated as an ordered character containing states of a morphological gradation from spatulate to subcaniniform crown morphology. Character 93 is a binary character where those species who have evolved state 1 can transform to this condition from all other incisors morphologies with the same cost to the analysis.

A parsimony analysis was conducted in PAUP 4.0a (Swofford, 2003) using the heuristic search, with equally weighted, ordered multistate characters. Like prior equally weighted heuristic searches of this brontothere data matrix (Mihlbachler, 2007b, 2008, 2011; Mihlbachler and Deméré, 2009; Mihlbachler and Samuels, 2016), resolution was 
uncovered from a poorly resolved strict consensus by removing wildcard taxa aposterior using reduced consensus techniques. Here, another approach was adopted using implied weighting measures (Goloboff et al., 2008) in TNT v. 1.5 software. Most parsimonious trees were recovered using default settings in a "New Technology Search". The search was commanded to continue until the most parsimonious tree length was recovered 300 times. The trees found during this search were subjected to extensive TBR branch swapping. Implied weighting analyses were done with $\mathrm{k}$ $=3,5,6,7$, using the same search parameters outlined above. A summary of the results of the implied weighting analyses showing the phylogenetic position of Protitanops curryi are seen in Figure 2. The full results of the PAUP-generated parsimony and implied weighting analyses are reported in Appendix 2.

\section{Institutional Abbreviations}

FMNH PM = Paleomammal Collection at the Field Museum of Natural History, Chicago; IGM = Museo de Paleontología of the Instituto de Geología of the Universidad Nacional Autónoma de Mexico; $\mathrm{LACM} / \mathrm{CIT}=$ California Institute of Technology now housed in the Los Angeles County Museum, Los Angeles; $\mathrm{OU}=$ Stovall Museum, University of OK, Norman; PIN = Paleontological Institute of the Russian Academy of Sciences, Moscow; TMM = Texas Memorial Museum, University of Texas, Austin; UCMP = University of California Museum of Paleontology, Berkeley; USNM = United States National Museum, Washington D.C.

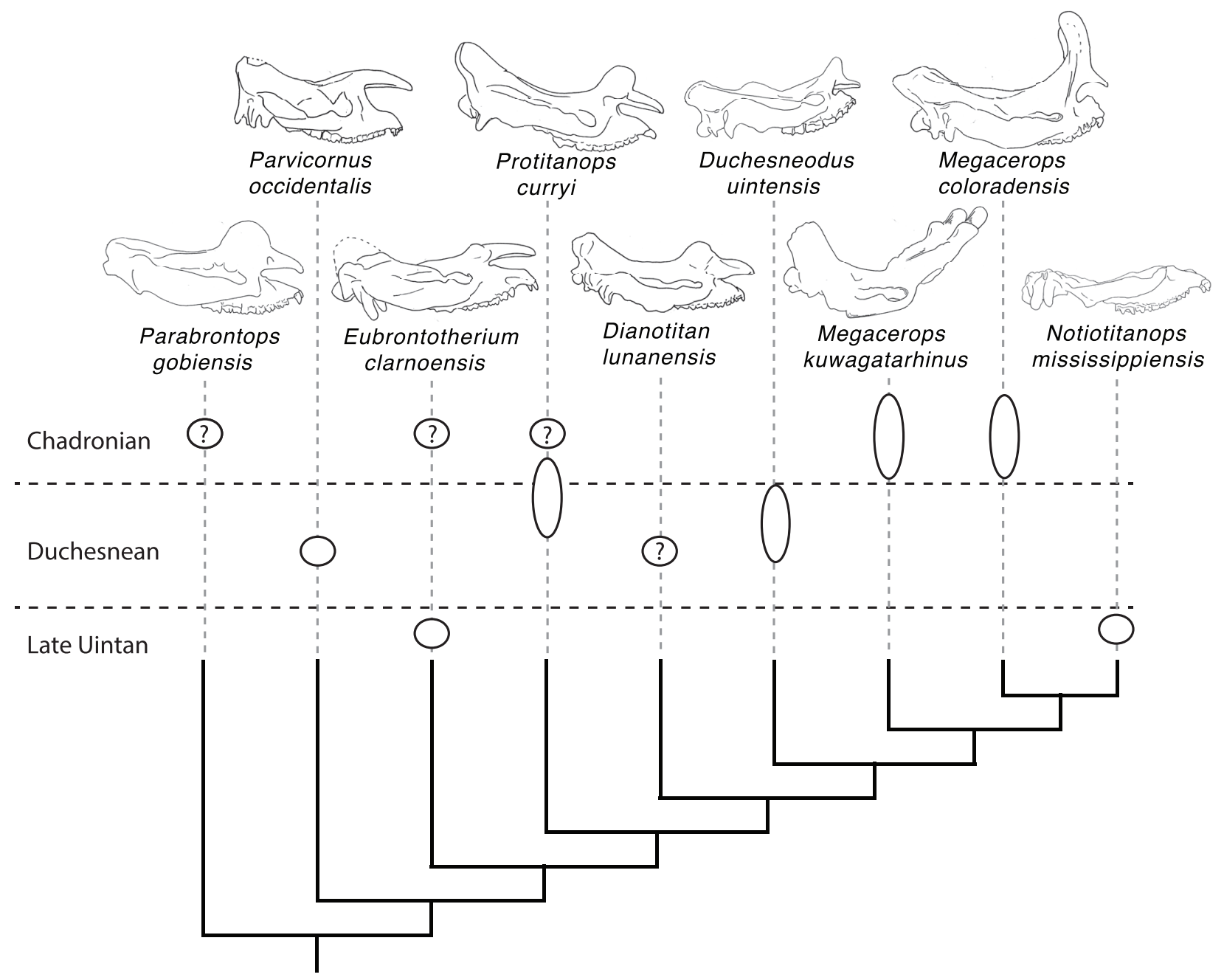

FIGURE 2. Strict consensus tree for infratribe Brontotheriita based on a parsimony search with implied weighting $(\mathrm{k}=7)$. Ovals represent stratigraphic distribution in North American Land Mammal Ages. The ages of Asian species with question marks are approximations based on Asian Land Mammal Age equivalence. 


\section{SYSTEMATIC PALEONTOLOGY}

Class MAMMALIA Linnaeus, 1758

Order PERISSODACTYLA Owen, 1848

Superfamily BRONTOTHERIOIDEA Marsh, 1873

Family BRONTOTHERIIDAE Marsh, 1873

Subfamily BRONTOTHERIINAE Marsh, 1873

Tribe BRONTOTHERIINI Marsh, 1873

Subtribe BRONTOTHERIINA Marsh, 1873

Infratribe BRONTOTHERIITA Marsh, 1873

Genus Protitanops Stock, 1936

Type and only known species. Protitanops curryi Stock, 1936.

Figures 3-10

Diagnosis. Protitanops curryi is a large-bodied brontothere with fronto-nasal horns that shares with other large horned brontotheres, Eubrontotherium clarnoensis, Notiotitanops mississippiensis, and Parvicornus occidentalis, the combination of an upper postcanine diastema and two pairs of upper incisors. P. curryi has large lateral zygomatic swellings that are not present in E. clarnoensis and $P$. occidentalis. P. curryi has more posteriorly positioned orbits and a less posteriorly extended nasal incision than $N$. mississippiensis.

Holotype. LACM/CIT 1854, a skull with complete dentition and a partial mandible with right $\mathrm{m} 3$, left $\mathrm{m} 1$ (partial), and m2-m3.

Holotype locality. Lower red beds of the Titus Canyon Formation in canyon east of Thimble Peak, Grapevine Mountains, California (Stock, 1936).

Stratigraphic horizon and age. Late Eocene (late Duchesnean and early Chadronian land mammal "ages")

Referred specimens. (From the Lower Chisos Formation, Big Bend National Park, Brewster County, Texas) TMM 40932-1, a partial skull with right P2-P3 (partial) and left P2-P4 (referred to Menodus bakeri by Wilson, 1977a); (from the "titanothere quarry", Lower Chisos Formation, Big Bend National Park, Brewster County, Texas) TMM 41916, a skull with complete dentition except the mesial incisor pair; TMM 41916-8, a partial juvenile skull with partial right dP2-dP4, left dP3 (partial), left dP4, unerupted right and left M1s; TMM 4191614, a transversely compressed juvenile skull and mandible in articulation with deciduous upper and lower incisors, canines, left cheek teeth including P1, dP2-dP4, p1, dp3-dp4, and unerupted adult molar crown; TMM 41916-19, a partial skull with right and left P2-M3; (from the Vieja Area, Chambers Tuff, Presidio County, Texas, Porvenir Local Fauna) FMNH PM 138, a dorsoventrally com- pressed skull with heavily worn and damaged cheek teeth; FMNH PM 157, a complete skull with right P3-M1, left C, P1-P4, M2, M3; FMNH PM 402, edentulous right and left mandibular rami; (from the Vieja Area, Blue Cliff Horizon of the Chambers Tuff, Presidio County Texas, Porvenir Local Fauna) FMNH P 137, a skull with heavily worn right and left cheek teeth; FMNH PM 139 a skull with heavily worn right and left cheek teeth and right and left mandibular rami with broken teeth; FMMH PM 168, mandible with right p3-m3; FMNH PM 205, a partial skull with partial right and left M1-M3; FMNH PM 398, a partial skull, right C, P2-M3, left C, P4-M3; FMNH PM 401, a mandible with complete symphysis, incisor row and damaged cheek teeth; FMNH PM 399, partial mandible with right c, p1-p4, m1m2 (partial), left p1-m3; (from the From Vieja Area, Big Red Horizon of the Chambers Tuff, Presidio County, Texas, Porvenir local fauna) TMM 458051 , a partial mandible with complete symphysis, right I1-I3, C, P1-P4, M1-M2 (partial), left I1-I3, C, $\mathrm{P} 2-\mathrm{M} 2, \mathrm{M} 3$ (partial); (from the Upper Conglomerate, Prietos Formation, Locality 1, $32 \mathrm{~km} \mathrm{NW}$ Ojinaga, Chihuahua, Mexico, Rancho Gaitan local fauna) IGM 65-29, a partial skull with right P2-M3; (from the Vieja Area, Chalk Gap Draw, Presidio County, Texas, Little Egypt Local Fauna) TMM 40840-38, a partial mandible with damaged cheek teeth; TMM 40840-39 a partial skull with damaged teeth.

\section{Description}

Skull. The type specimen (LACM/CIT 1854) is a complete skull and partial mandible (Figure $3 \mathrm{~A}$ ) that is more extensively described and figured elsewhere (Mihlbachler, 2008). The description below emphasizes new information based on the newly referred specimens from Texas and Mexico. Numerous whole and partial skulls have been recovered from the Chisos Formation and the Chambers Tuff of the Vieja area from West Texas. The most complete Chambers Tuff skull (FMNH PM 157) is undistorted and best preserves the overall shape of the cranium (Figure 4). Other Vieja specimens (FMNH PM 137, 138, 139, 205, and 398) are skulls with advanced stages of dental wear. These specimens provide important details on phenotypic variation in adult $P$. curryi. The Chisos material is taphonomically deformed to a greater extent but finer details of bone and teeth are preserved. The Chisos material includes more immature individuals including several dentally subadult specimens with deciduous teeth (TMM 41916-14, Figure 5) (TMM 41916-8, Figure 6), 


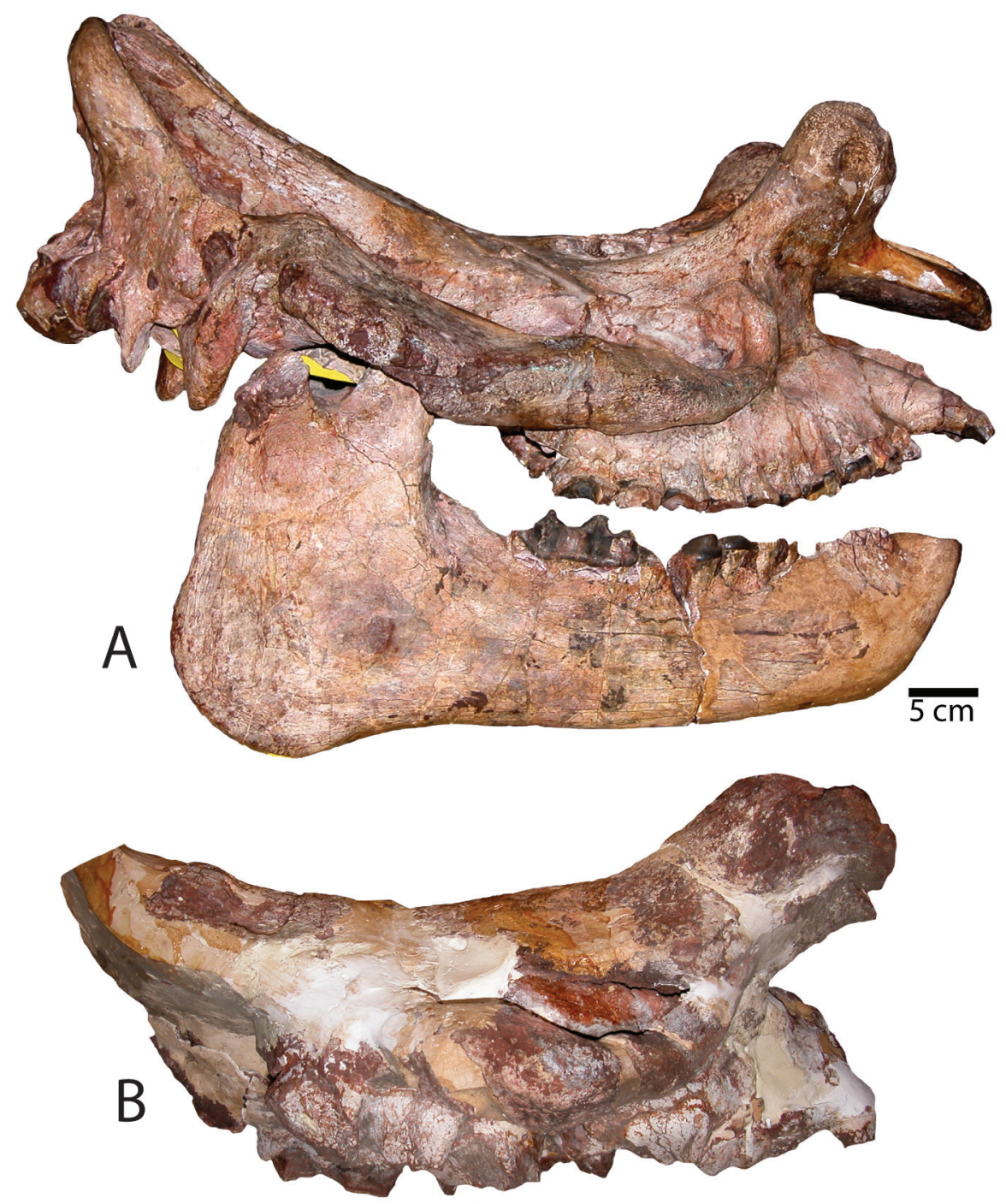

FIGURE 3. (A) The holotype of Protitanops curryi Stock 1936 (LACM/CIT 1854) and (B) a stratigraphically associated but larger specimen previously referred to as Menodontine (?) by Stock (1936) that is possibly P. curryi (LACM/CIT 2007).

other specimens with lightly worn adult dentitions (TMM 41916-6; Figure 7), (TMM 41916-19), and one older adult with more heavily worn teeth (TMM 40932-1, Figure 8). Additional specimens of $P$. curryi include the partial adult skull from the Rancho Gaitan local fauna (IGM 65-29, Figure 9). This specimen has experienced some dorsoventral flattening, and it is lacking the anterior dentition, the occiput, and much of the left side of the skull.

The frontonasal horns of $P$. curryi are short knobs, project dorsolaterally and slightly anteriorly, and they are elliptical with the longest axis in the antero-posterior direction. The horns of the adult specimens are observed to range from $80-140 \mathrm{~mm}$ in length from the proximal base to the apex with observed circumferences ranging from 220-300 $\mathrm{mm}$ (Table 1). As with other brontotheres, horn size appears related to ontogenetic age. In the subadult skulls (TMM 41916-14, 41916-8) (Figures 5, 6) horns are in evidence but they are very small protrusions with between 10-20 mm of relief. In those specimens, the proximal base of the horn, formed by the nasal bone, is unfused to the horn apex, which is formed by a thickened anterior projection of the frontal bone. One Chisos skull (TMM 419166 ) is an ontogenetically younger specimen with erupted but unworn M3s. This specimen has small incompletely co-ossified frontonasal horns. The proximal base of the horn, formed by the nasal bone, is unfused to the horn apex which is formed by a thickened anterior projection of the frontal bone. In more dentally mature specimens (Figures 


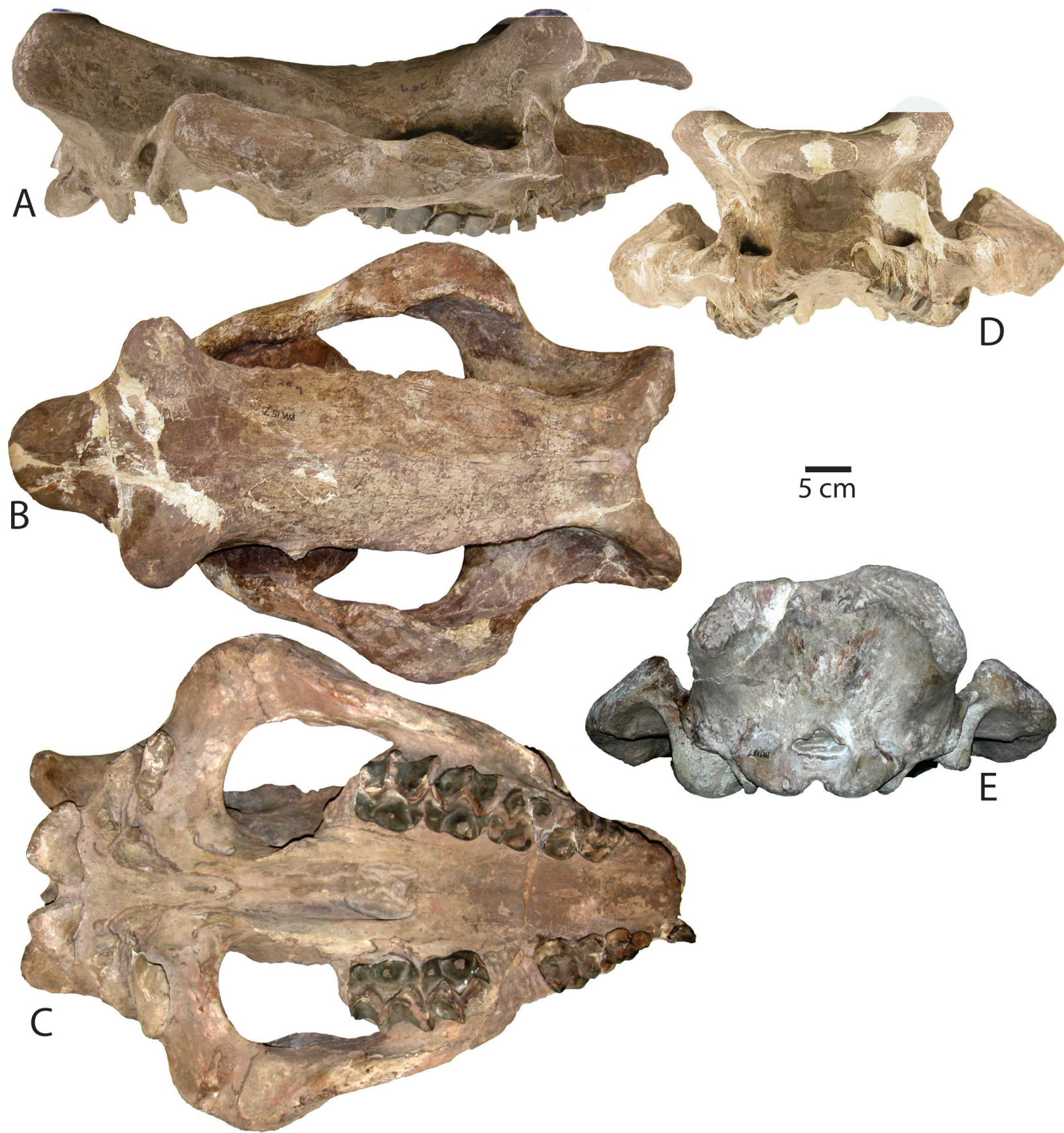

FIGURE 4. A skull (FMNH PM 157) from the Blue Cliff Horizon of the Chambers Tuff Formation referred to Protitanops curryi: $(A)$ right view, $(B)$ dorsal view, $(C)$ ventral view, (D) anterior view, (E) posterior view.

$3,4,8)$ the frontonasal horns are fully co-ossified, and the frontonasal interface is no longer evident. The variation seen between young and older specimens here is a typical ontogenetic trajectory observed in other species of horned brontotheres (Mihlbachler, 2007b, 2008, 2011; Mihlbachler and Deméré 2009). Most of the specimens referred to Protitanops curryi are larger, more robust "malelike" specimens (FMNH PM 137, FMNH PM 138,
FMNH PM 139, FMNH PM 157; IGM 65-29; TMM 40932-1). A smaller number of individuals (FMNH PM 205, FMNH PM 398) have smaller, shorter horns, although in both of these specimens the horns are insufficiently preserved for accurate measurement.

The anterior margin of the nasal process sometimes has a median notch where the right and left nasal bones are incompletely fused. In more 


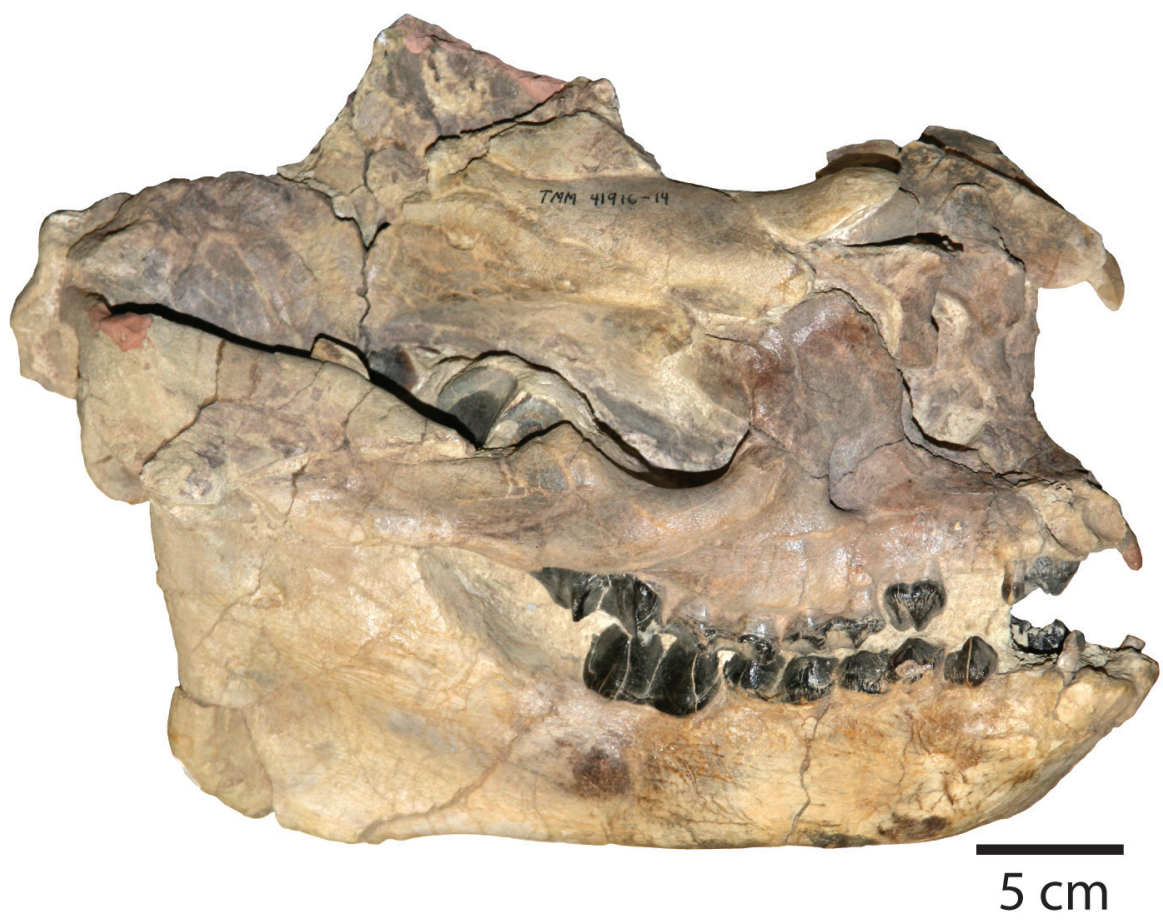

FIGURE 5. A juvenile skull (TMM 41916-14) from the "titanothere quarry" of the Lower Chisos Formation referred to Protitanops curryi.

dentally advanced adults this notch is absent and the nasals are more fully co-ossified.

The orbit of the type specimen is positioned directly above the posterolateral root of $\mathrm{M} 1$ and the anterolateral root of M2. In the Texas specimens, the orbit is similarly positioned, but can be slightly more anteriorly positioned (TMM 41916-6) but not to the extent that it alters how phylogenetic character 13 (related to the position of the orbit) is coded. Similarly, minor amounts of intraspecific variability in the position of the orbit with respect to the molars is observed in Duchesneodus uintensis and Parvicornus occidentalis (Mihlbachler, 2008; Mihlbachler and Deméré, 2009).

The type specimen from California has the most deeply concave dorsal profile of all the skulls. In Texas specimens (TMM 41916-6, FMNH PM 157), the dorsal surface of the skull is less deep but still convex (saddle shaped) from above the orbits to the dorsal rim of the occiput. Taphonomic dorsoventral flattening may distort the apparent depth of the concave dorsal profiles of some of these skulls.

The degree to which the parasagittal ridges converge posteromedially and constrict the posterodorsal surface of the skull is intraspecifically variable in Protitanops curryi and other brontotheres (Mihlbachler, 2011). The degree of constriction is most pronounced in the type specimen and Chisos specimens (TMM 41916-6, Figure 7; TMM
40932-1, Figure 8). The parasagittal ridges are more widely spaced in the subadult Chisos specimen (TMM 41916-8, Figure 6), other adult Vieja specimens (FMNH PM 137; FMNH PM 157, Figure 4; FMNH PM 205; FMNH PM 398), and the Prietos skull (IGM 65-29, Figure 9).

The zygomatic arches of $P$. curryi are expanded laterally with swellings at the junction of the jugal and squamosal. The swellings range from 40-98 mm in thickness. Protitanops curryi was previously described as having a straight zygomatic arch (Mihlbachler, 2008). This assessment was based on the left zygomatic arch of the type specimen. However, the left zygomatic arch of the type is damaged and has been partly reconstructed with plaster. On the right side of the type specimen, and in Texas specimens with whole, undistorted zygomatic arches, the temporal part of the zygomatic arch is angled posterodorsally, giving the zygomatic arch a curved appearance from lateral views of these skulls. The degree of curvature is variable, and seems more pronounced in the more robust specimens suggesting it could be an aspect of sexual dimorphism.

From a dorsal view, the nuchal crest (the postero-dorsal edge of the skull) is thicker and more rugose in some specimens (Figure 4), and thinner and smoother in others. The nuchal crests of all of the Texas skulls have a broadly concave curvature 


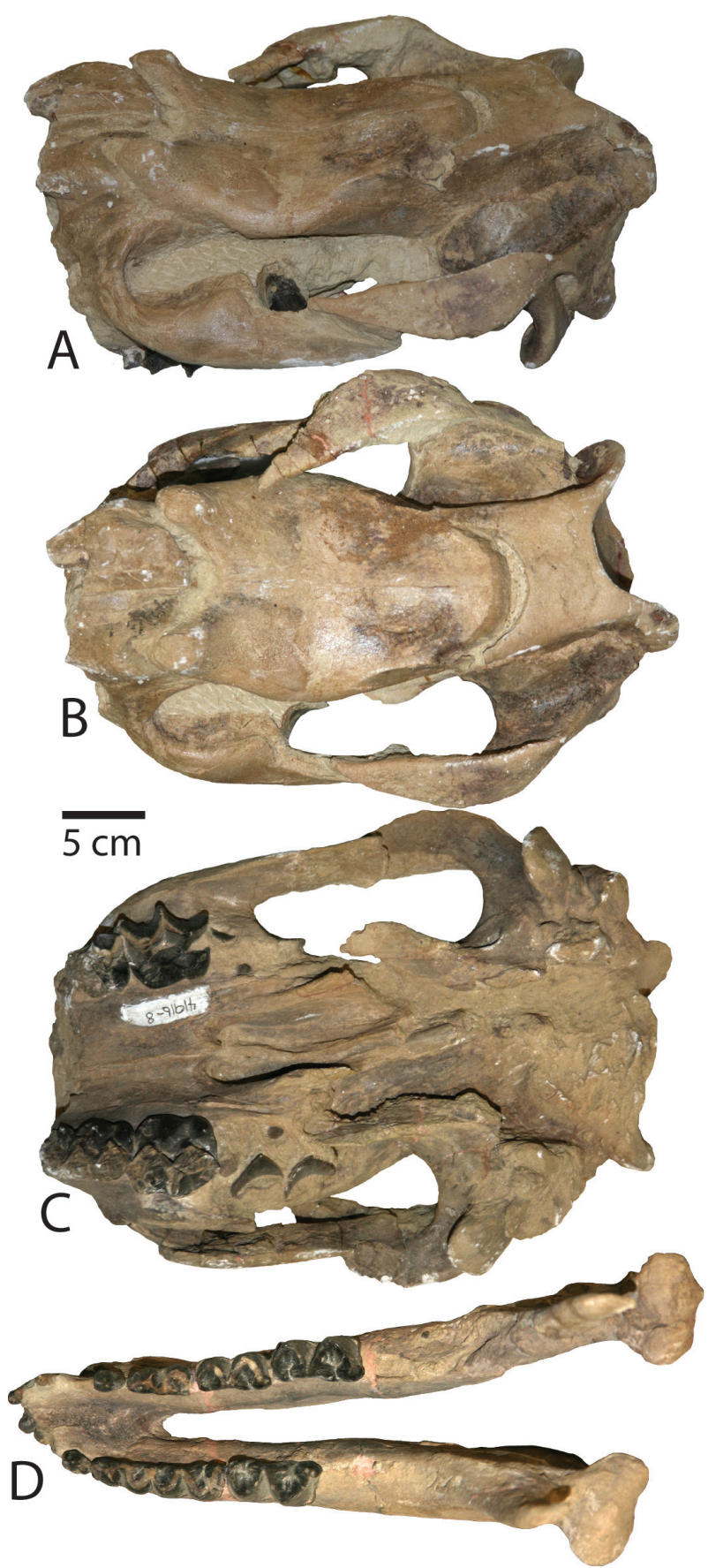

FIGURE 6. A juvenile skull (TMM 41916-8) from the "titanothere quarry" of the Lower Chisos Formation referred to Protitanops curryi: (A) left view, (B) dorsal view, (C) ventral view, (D) mandible.

when viewed from a dorsal perspective. The nuchal crest of the type specimen is more sharply notched mesially, although this difference may be a consequence of damage; parts of the bone surface appear to have been broken away along the rim of the nuchal crest. From a posterior view, the occiput of FMNH PM 157 (Figure 4E) closely resembles the type; the dorsal portion of the occiput is similar in width to the ventral portion, and it is slightly constricted in the middle. The occipital pillars are similarly large with a deep central depression. The occiput of TMM 41916-6 (Figure 7D) is shaped differently; the dorsal portion of the occiput is narrower than the ventral portion and it is less constricted in the middle.

In the type specimen, the posterior edge of the palatine bone (which forms the anterior margin of the posterior nares) is between the right and left M3s, just slightly posterior to the protocones. This same margin in the Texas specimens is consistently more anteriorly positioned, and there is some variation in its exact position with respect to the dentition. Some of this variation may be ontogenetic and relate to remodeling of the skull in association with eruption and wear of the dentition throughout life. The type specimen, in which the posterior nares are the most posteriorly situated among all known $P$. curryi skulls, is also one of the most ontogenetically advanced specimens, based on the state of dental wear. TMM 41916-19 (unfigured) is ontogenetically the youngest individual in the sample with a completely erupted set of adult dentition, with an unworn left M3 and barely worn right M3. In this specimen, the anterior margin of the posterior nares is positioned anterior to the M3s. In other adult Texas specimens, including the young adult TMM 41916-6 (Figure 7C) and more advanced adults with more substantial dental wear, the anterior margin of the posterior nares is between the M3 protocones or slightly anterior to the protocones.

The elongate posterior narial canal, a feature associated with the elongated postorbital cranium of brontotheres, is divided by an elongate thin vomer. The vomer is damaged or unpreserved in most specimens, but can be readily seen in the ventral view of TMM 41916-6 (Figure 7C). In that specimen, sediment still fills the roof of the posterior narial canal but it has been fully cleared of sediment at its posterior end. The vomer continues in the posterior narial canal and terminates posteriorly at the midline of the skull between the foramina ovale of the basicranium.

The tube-shaped external auditory pseudomeatus is visible in all the large adult specimens. This shape is created by the mastoid process, which curves anteriorly and contacts the postglenoid process, forming an enclosed canal.

Upper dentition. The upper dental formula of Protitanops curryi is $2 / 1 / 4 / 3$. The type of $P$. curryi 


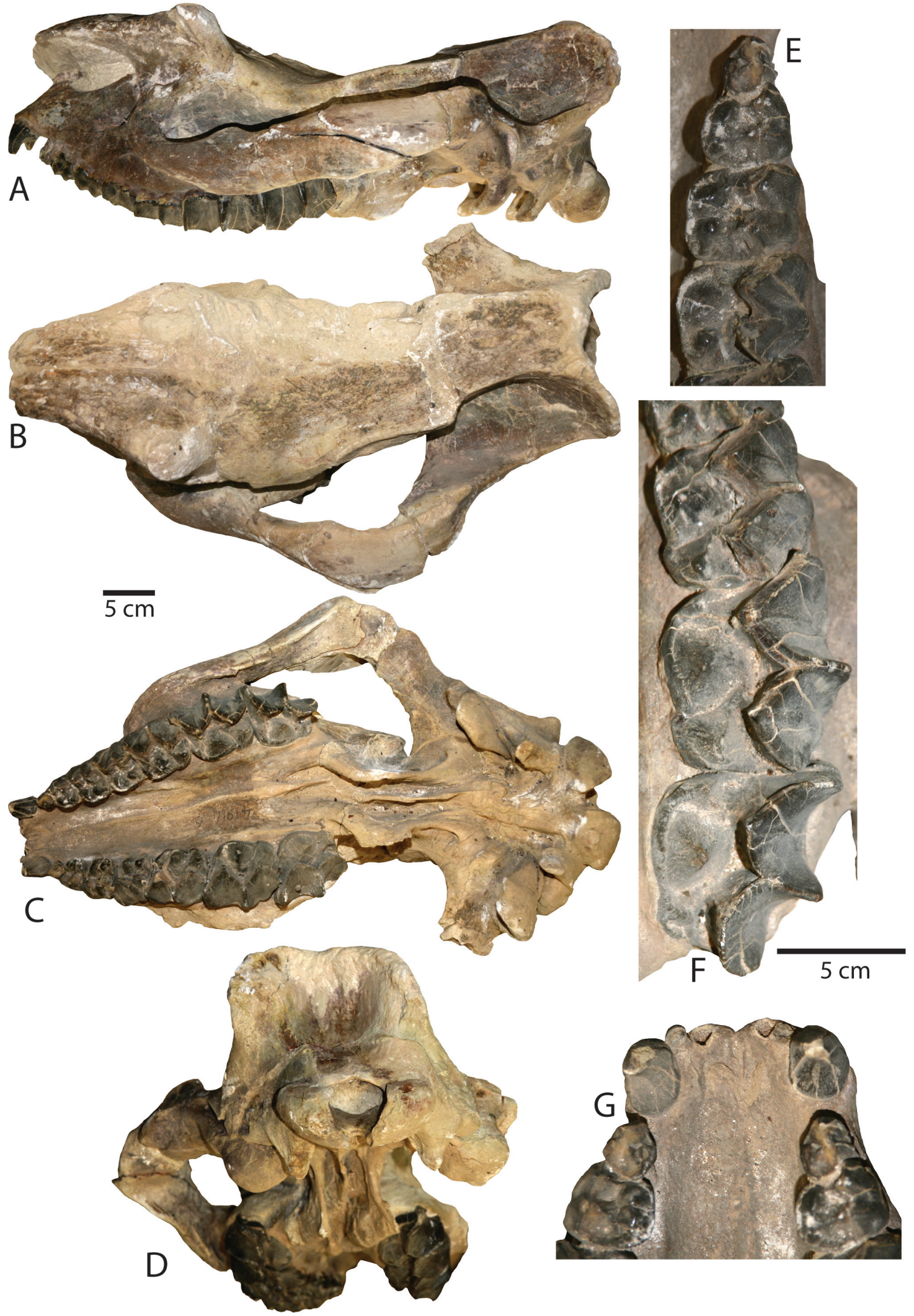

FIGURE 7. A skull (TMM 41916-6) from the "titanothere quarry" of the Lower Chisos Formation referred to Protitanops curryi: (A) left view, (B) dorsal view, (C) ventral view, (D) posterior view, (E) left P1-P4, (F) anterior dentition, (G) left M1-M3. 


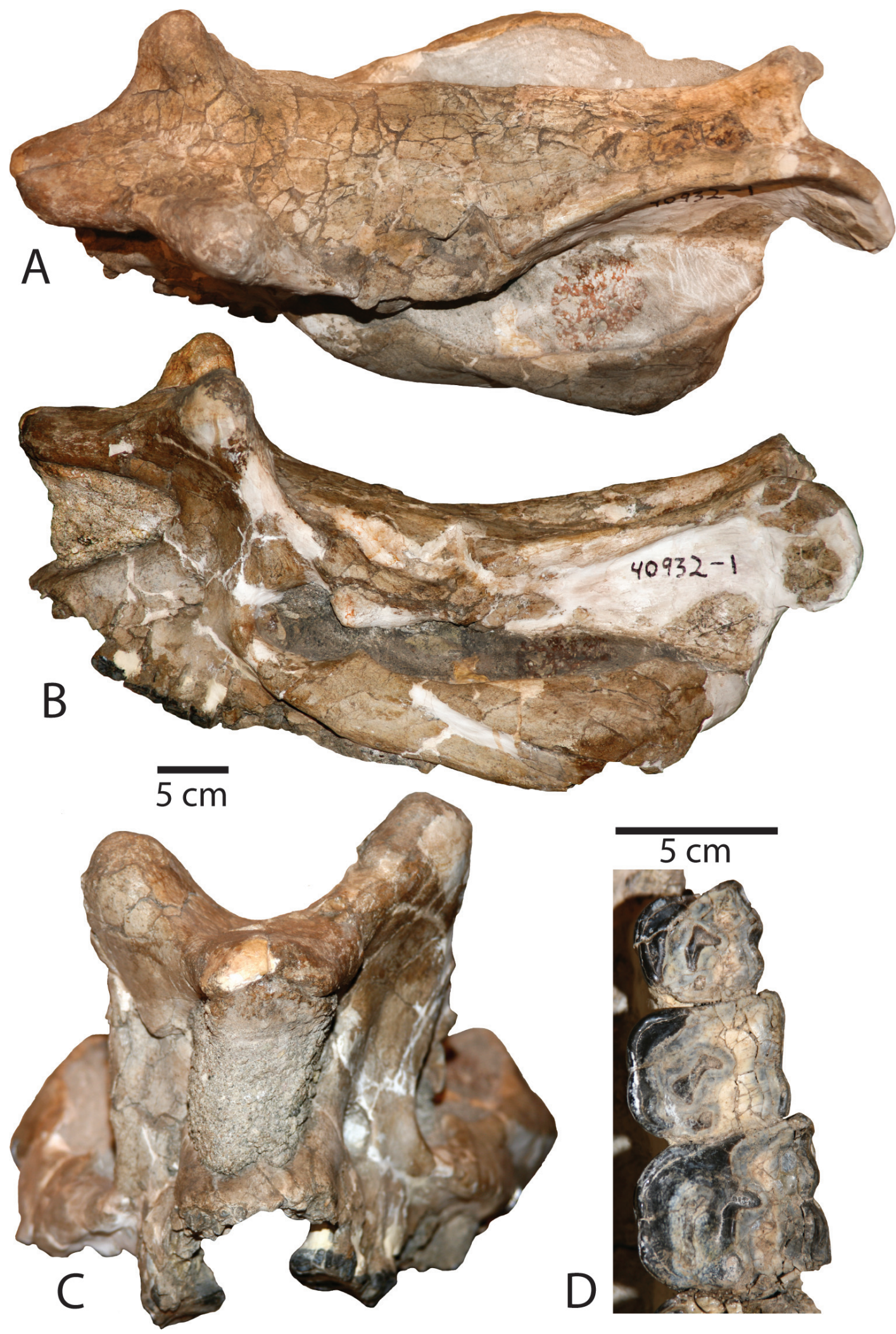

FIGURE 8. A skull (TMM 40932-1) from the Lower Chisos Formation previously referred to Menodus bakeri by Wilson (1977a), now referred to Protitanops curryi: (A) dorsal view, (B) left view, (C) anterior view, (D) left P2-P4. 


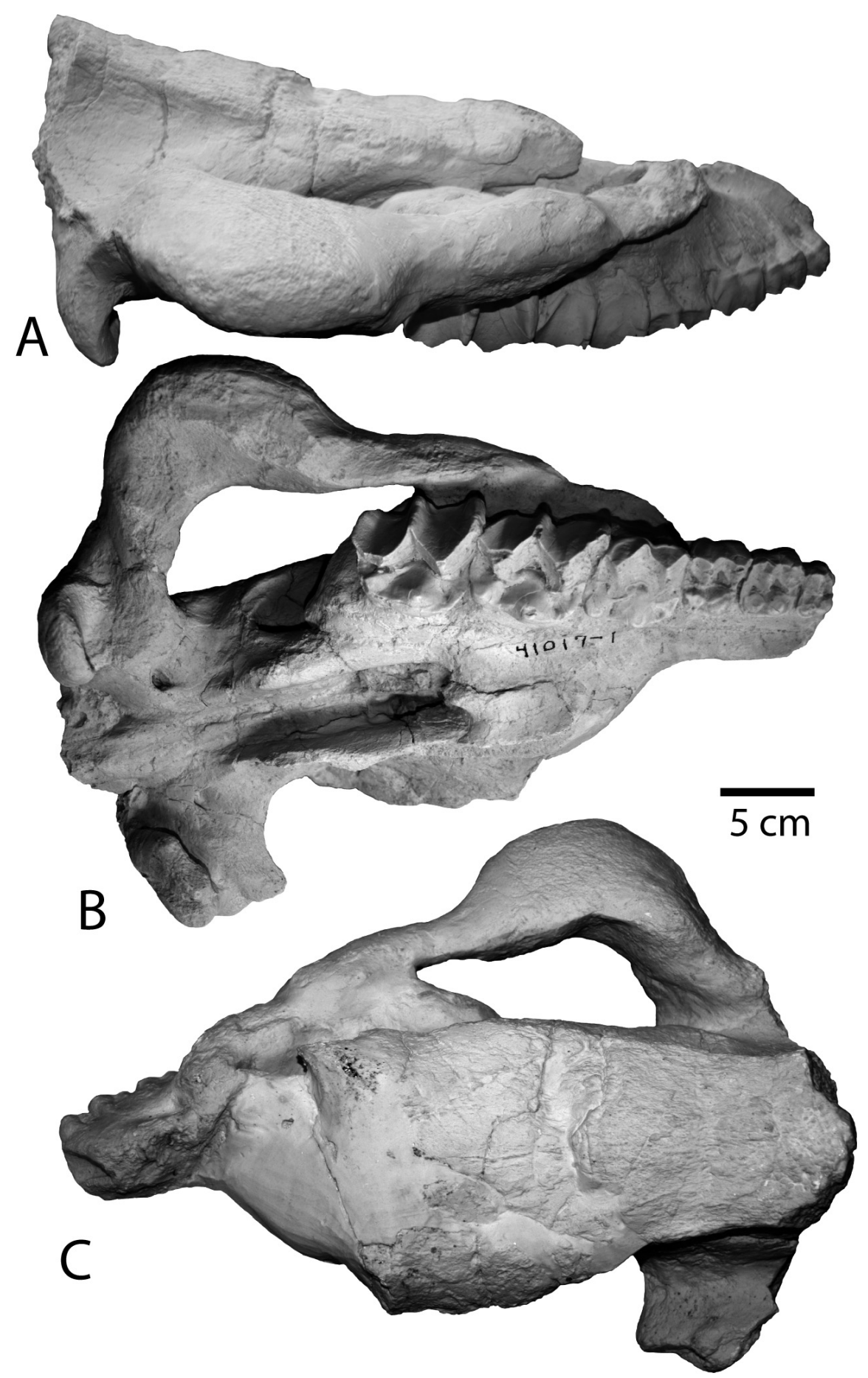

FIGURE 9. A partial skull (IGM 65-29) from the Prietos Formation previously referred to ?Brontops cf. brachycephalus by Ferrusquia-Villifranca (1967), now referred to Protitanops curryi: (A) right view, (B) ventral view, (C) dorsal view. (The number 41017-1 written on the figured specimen is the catalog number of the cast in the TMM collection.)

has two pairs of very small amorphous incisors separated by a brief mesial diastema. The dentition of TMM 41916-6 is figured in closeup (Figures 7F$\mathrm{G})$. Several Texas specimens have incompletely preserved incisors and or incisor alveoli that indi- cate the same dental formula with two very small incisor pairs separated by a mesial diastema and positioned along the anterior edge of the canines in a straight row. The upper canine crowns are 24-30 $\mathrm{mm}$ diameter. The canine diameter of the type 


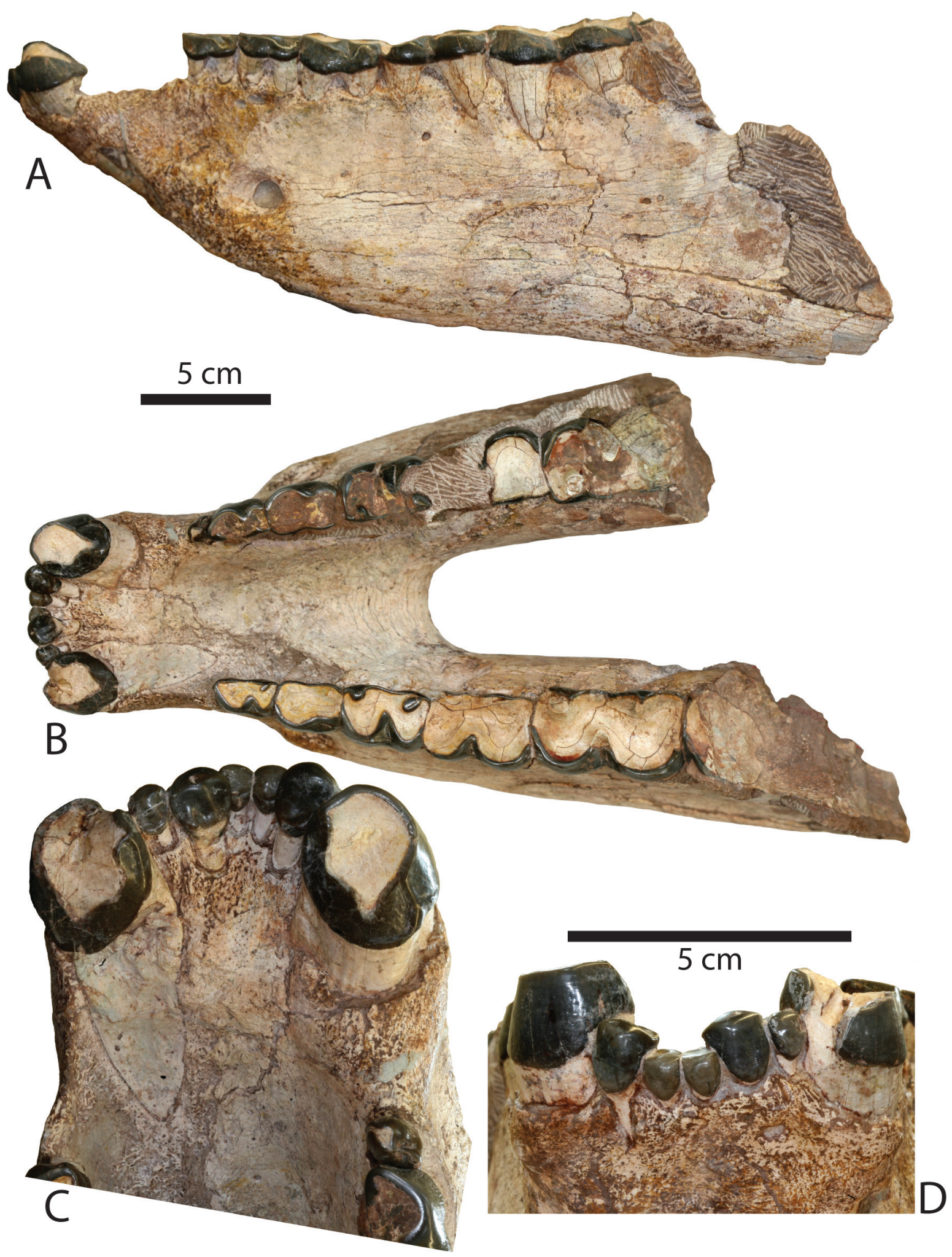

FIGURE 10. A mandible (TMM 45805-1) from the Big Red Horizon of the Chambers Tuff referred to Protitanops curryi: (A) left view, (B) dorsal view, (C) occlusal view of anterior dentition (D) labial view of anterior dentition. 
TABLE 1. Selected measurements for type specimen (LACM/CIT 1854) of Protitanops curryi, a stratigraphically associated and possibly conspecific specimen (LACM/CIT 2007), and summary statistics for Protitanops curryi material from West Texas and Mexico combined. Abbreviations: $\mathrm{N}$ - number of specimens; SD - standard deviation; Min - minimum observation; Max - maximum observation; CV - coefficient of variation.

\begin{tabular}{|c|c|c|c|c|c|c|c|c|}
\hline & \multicolumn{2}{|c|}{ Titus Canyon } & \multicolumn{6}{|c|}{ West Texas specimens combined } \\
\hline & $\begin{array}{c}\text { LACM } \\
\text { /CIT } 1854\end{array}$ & $\begin{array}{c}\text { LACM } \\
\text { /CIT } 2007\end{array}$ & $\mathbf{N}$ & Mean & SD & Min & Max & CV \\
\hline ventral skull length & 688 & & 4 & 663 & 25 & 642 & 698 & 4 \\
\hline proximodistal horn length & 134 & & 2 & 110 & 42 & 80 & 140 & 39 \\
\hline horn circumference at proximal base & 277 & & 5 & 248 & 34 & 220 & 300 & 14 \\
\hline thickness of zygomatic arch & 88 & & 6 & 82 & 22 & 40 & 98 & 26 \\
\hline upper canine crown width & 23 & & 3 & 26 & 3 & 24 & 30 & 11 \\
\hline P3 mesiodistal length & 29 & 37 & 8 & 33 & 3 & 30 & 37 & 9 \\
\hline P3 labiolinugal width & 38 & 46 & 8 & 41 & 3 & 35 & 45 & 8 \\
\hline M2 mesiodistal length & 65 & 83 & 6 & 72 & 4 & 68 & 79 & 6 \\
\hline M2 labiolingual width & 64 & 69 & 6 & 69 & 5 & 60 & 72 & 7 \\
\hline P2-P4 mesiodistal length & 84 & & 6 & 100 & 6 & 91 & 104 & 6 \\
\hline M1-M3 mesiodistal length & 182 & & 5 & 195 & 19 & 180 & 225 & 10 \\
\hline lower canine crown width & & & 3 & 28 & 8 & 19 & 36 & 30 \\
\hline p3 mesiodistal length & & & 2 & 30 & 3 & 28 & 32 & 10 \\
\hline p3 labiolingal width & & & 2 & 22 & 2 & 20 & 23 & 10 \\
\hline m2 labiolingual length & & & 4 & 38 & 3 & 33 & 40 & 9 \\
\hline $\mathrm{m} 2$ mesiodistal length & 57 & & 4 & 63 & 4 & 58 & 68 & 6 \\
\hline p2-p4 mesiodistal length & & & 3 & 90 & 2 & 89 & 92 & 2 \\
\hline m1-m3 mesiodistal length & 190 & & 3 & 220 & 20 & 200 & 240 & 9 \\
\hline
\end{tabular}

specimens as at the lower end of this range $(23$ $\mathrm{mm})$. A short postcanine diastema is consistently present and ranges from $5-11 \mathrm{~mm}$. The persistence of a postcanine diastema differentiates $P$. curryi from Dianotitan lunanensis, Duchesneodus uintensis, Megacerops coloradensis, and M. kuwagatarhinus, which all lack an upper postcanine diastema.

The premolars of the holotype lack some character information due to wear. The adult premolars of TMM 41916-6 are less worn (Figure 7E). The P1 is smaller than more posterior premolars, with a more obliquely angled mesial edge. Two labial cusps (paracone and metacone) are present. The lingual side of the $\mathrm{P} 1$ forms a small lingual heel with two small but distinct cusps, protocone and hypocone, that are connected by a short crest. The P2, P3, and P4 are more rectangular in outline with more nearly parallel anterior and posterior sides. The parastyle of $\mathrm{P} 2$ extends anteriorly while the parastyles of P3 and P4 are deflected progressively more labially. The premolar metastyles are consistently directed posteriorly. A P4 mesostyle, which is variably present and absent in some species (e.g., Eubrontotherium clarnoensis, Duch- esneodus uintensis, Parvicornus occidentalis) does not occur on any of the specimens referred to Protitanops curryi. Small preprotocristae are discernable on the P2-P4. On P3 and P4, the preprotocristae are visible as small crests or beads of enamel that connect the protocone to the lingual base of the protocone. The lingual cusps of the P2 of TMM 41916-6 are connected by a thin, poorly developed crest. The lingual cusps of the P3 and P4 of the same specimen are fully separated, and no lingual connecting crests are seen. In other specimens (FMNH PM 157, TMM 40932-1, Figure 7D; TMM 41916-19) the lingual cusps are more strongly connected by a connecting crest. This crest tends to be tallest on the P2 and becomes progressively shorter in more posterior premolars. The variable morphology of the lingual sides of the premolars is consistent with patterns of premolar variation seen within many other brontothere species (Mihlbachler, 2008).

The molars of the type are heavily worn, although the lesser worn molars of TMM 41916-6 (Figure 6G) and other specimens more fully reveal a complete suite of molar traits. The molars of Protitanops curryi lack diagnostic autapomorphies 
and show a suite of conserved characteristics that characterize members of the subfamily Brontotheriinae, including tall, lingually angled ectolophs, very weak labial ribs, and thin lingual ectoloph enamel. The anterior cingulum is thin and passes proximally to the distal peak of the parastyle. The lingual margins of the paracone and metacone are wedge shaped. Distinct central molar fossae and anterolingual cingular cusps are seen on all three molars. As in many other brontotheres, the hypocone of the M3 is variable. In the type, there is no distinct hypocone on $\mathrm{M} 3$, although a crest extends from the distolingual corner of the M3 to the lingual base of the metacone. The M3 of TMM 41916-6 has a distinct hypocone that is smaller than the hypocones of more anterior molars. FMNH PM 157 (Figure 4C) has a larger, more molariform hypocone. Most other Texas specimens have intermediately sized hypocones.

Mandible and lower dentition. The type of $P$. curryi includes a poorly preserved mandible with heavily worn and incompletely preserved dentition. FMNH PM 139 includes an associated skull and right and left mandibular rami. However, these rami are incomplete, edentulous and, on the whole, not very informative. However, a number of mandibles from the Vieja area (FMNH PM 168, 399, 401, 402; TMM 40840-38, 45805-1) have been recovered, and although these are unassociated with cranial remains, the dimensions of these specimens are above the size range of Duchesneodus uintensis, the only known brontothere whose stratigraphic ranges overlap. They are similar in size and morphology to the type mandible of $P$. curryi and are therefore referred to that species.

The best preserved and most character-rich mandible referred to Protitanops curryi is TMM 45805-1 (Figure 9), which consists of a complete mandibular ramus with right and left anterior dentition and premolars. The transverse width of this mandible at the canines is similar to the width of the mandible at the P2. In lateral view, the inferior margin of the symphysis is angled slightly less than 45 degrees from the horizontal and its slightly convex shape transitions smoothly into the inferior ventral surface of the horizontal ramus. Other specimens have similarly shaped and proportioned mandibles but they are less finely preserved. The posterior margin of the mandibular symphysis of TMM 45805-1 is positioned between the posterior edges of P4. In other mandibles (FMNH PM 399, 401), the posterior margin of the symphysis is just slightly anterior to the posterior edge of P4. The observed fluctuation in the length and position of the symphysis with respect to the dentition is minor and easily fits within a single character state (Character 71 , state 3 ). Similar variation is seen in other brontothere species and may relate to remodeling of the mandible in association with eruption and wear of the dentition throughout life.

The mandibular dental formula of Protitanops curryi is $3 / 1 / 4 / 3$. Although the incisors and canines are not preserved in the type, two of the Texas specimens (FMNH PM 401, TMM 45805-1) retain five lower incisors (two right and three left). In both specimens the right i3 appears to have been lost in life with the alveolus having been lost due to subsequent bone remodeling (Figure 10C). The incisor row forms a subtle arch between the canines. The incisor row is less arched than that of Parvicornus occidentalis and more similar to the flatter incisor row of Eubrontotherium clarnoensis. There are no diastemata anterior to the canines and even the space that the missing right i3 would have been occupied has been closed. The i1 and i3 are small and of similar size, while the i2 is larger. The apices of the incisor crowns are worn flat; however, the labial edges of the incisor crowns have a wedgeshaped appearance. Each incisor has a distinct lingual heel. Similarly, the canines of TMM 45805-1 are worn flat. Lower canine size, which is likely to be a sexually dimorphic trait in brontotheres (Mihlbachler 2011), is variable, with crown diameter ranging from 19-36 $\mathrm{mm}$. All mandibles retain a postcanine diastema that is roughly similar in length or slightly longer than the antero-posterior length of the p2. A diastema between the p1 and $\mathrm{p} 2$ is not present.

The mandibles referred to Protitanops curryi all have poorly preserved or heavily worn cheek teeth. Nonetheless, the overall morphology and proportions of the cheek teeth appear to be undifferentiated from Eubrontotherium clarnoensis, Parvicornus occidentalis, and Duchesneodus uintensis. The p1 of TMM 45805-1 (preserved on the left side) is small with a single cusp and a small broad talonid heel and is rooted in the mandible vertically. The p2 trigonid is anteroposteriorly longer than the talonid, but not more than twice as long. All of the occlusal features of the p3 are worn away. The trigonid and talonid of p2 have similar bucco-lingual widths. A cristid obliqua is seen on the left $\mathrm{p} 2$, but is more worn on the right $\mathrm{p} 2$. The notch on the labial side of the p2 formed by the cristid obliqua is relatively broad in this respect resembles other closely related species, and differs from some large Asian species that have a much deeper and narrower labial notch. The p4 tri- 
gonid and talonid are similar in length and width, while other features of the p4 have been worn away. The teeth are too worn to make determinations about the presence or absence of metaconids on the premolars. Other specimens (FMNH PM 399, TMM 40840-38) have more completely preserved molars. The molars of these specimens, like many brontotheres, are conserved; they lack autapomorphous features or species-specific combinations of characters. Typical characteristics include shallow occlusal basins, thinned lingual enamel, and an elongate $\mathrm{m} 3$.

\section{cf. Parvicornus occidentalis}

Stratigraphic horizon and age. Late Eocene (Duchesnean mammal "age."

Referred specimens. (From the Skyline Channels, Devil's Graveyard Formation, Aqua FriaGreen Valley Area of Trans Pecos Texas) TMM 41853-17, a palate with complete dentition; TMM 41850-30, a rostral fragment with complete incisor row and right canine; TMM 41715-6, left mandibular ramus with p2 (partial), p3-m3; TMM 42254-2, a right ramus with $\mathrm{p} 2-\mathrm{m} 3$.

\section{Description}

The two cranial specimens, TMM 41853-17 (Figure 11A-C) and 41850-30 (Figure 11D-F) have complete incisor rows with two small incisor crowns per side, slightly arched incisor rows and a distinct postcanine diastema. The incisors have a short pointed apex, blunted somewhat by apical wear that is more prominent in the lateral incisor giving it a subtle caniniform appearance. The mandibular symphyses of TMM 41715-6 (Figure 11G) and TMM 42254-2 (Figure 11H) extend posteriorly as far as the trigon of the P3. The weakly arched shape of the incisor row and the position of the posterior margin of the mandibular symphysis (anterior to p4) is most consistent with Parvicornus occidentalis. One mandible (TMM 41715-6) has a postero-lingually angled cristid obliqua and p3 metaconid. Metaconids are variably present and absent in $P$. occidentalis, therefore this character would not contradict an assignment to cf. P. occidentalis.

The early Duchesnean specimens from the Skyline Channels tentatively referred to cf. Parvicornus occidentalis were previously referred to ?Duchesneodus cf. uintensis primarily on the basis of size by Wilson and Stevens (1986). However, unlike specimens described here, Duchesneodus uintensis lacks an upper postcanine diastema and has a more posteriorly situated mandibular symphysis. Other species can also be ruled out with some certainty: Parabrontops gobiensis retains three upper incisors; Dianotitan lunanensis lacks a postcanine diastemata; Protitanops curryi, Notiotitanops mississippiensis, and Eubrontotherium clarnoensis also have more posteriorly extended mandibular symphyses.

\section{DISCUSSION}

\section{Taxonomic Identity of Protitanops curryi}

Protitanops curryi was based on a skull and partial mandible from the early Chadronian Titus Canyon Formation of California (Figure 3A). Until now, only the type specimen has been referred to the species. Stock (1936) also described a partial skull (LACM/CIT 2007, Figure 3B) from a similar stratigraphic position as the type of $P$. curryi, but he referred it to it as "Menodontine(?)". The specimen is too incomplete to determine its specific identify and although it is larger, it does not possess characters that contradiction $P$. curryi; therefore, it could be a larger member of the same species. Table 2 summarizes character state differences among species of Brontotheriita and compares them to the newly described material from West Texas and Mexico. Chambers Tuff, Chisos, and Prietos Formations. These specimens from the Chambers Tuff, Chisos, and Prietos Formations have congruent sets of character states and are therefore consistent with a single species. On the other hand, the material from the Devil's Graveyard Formation appears not to belong to the same species due to some character differences, including a slightly more arched incisor row, more conular upper incisors and a more anteriorly positioned mandibular symphysis. Unfortunately, more diagnostic material for the Devil's Graveyard formation is lacking and for the time being, this material is referred to c.f. Parvicornus occidentalis due to congruency with that species among the existing character data.

Returning to consideration of the Chambers Tuff, Chisos, and Prietos material, only a single character difference was located in comparing these specimens to the type of $P$. curryi (LACM/CIT 1854). The anterior margin of the posterior nares is more posteriorly shifted in the type of $P$. curryi (character 28). This variation could be partly ontogenetic and relate to remodeling of the skull in association with eruption and wear of the dentition throughout life. Similar intraspecific variation in the position of the posterior nares with respect to the molars is observed in referent quarry samples Duchesneodus uintensis and Parvicornus occiden- 


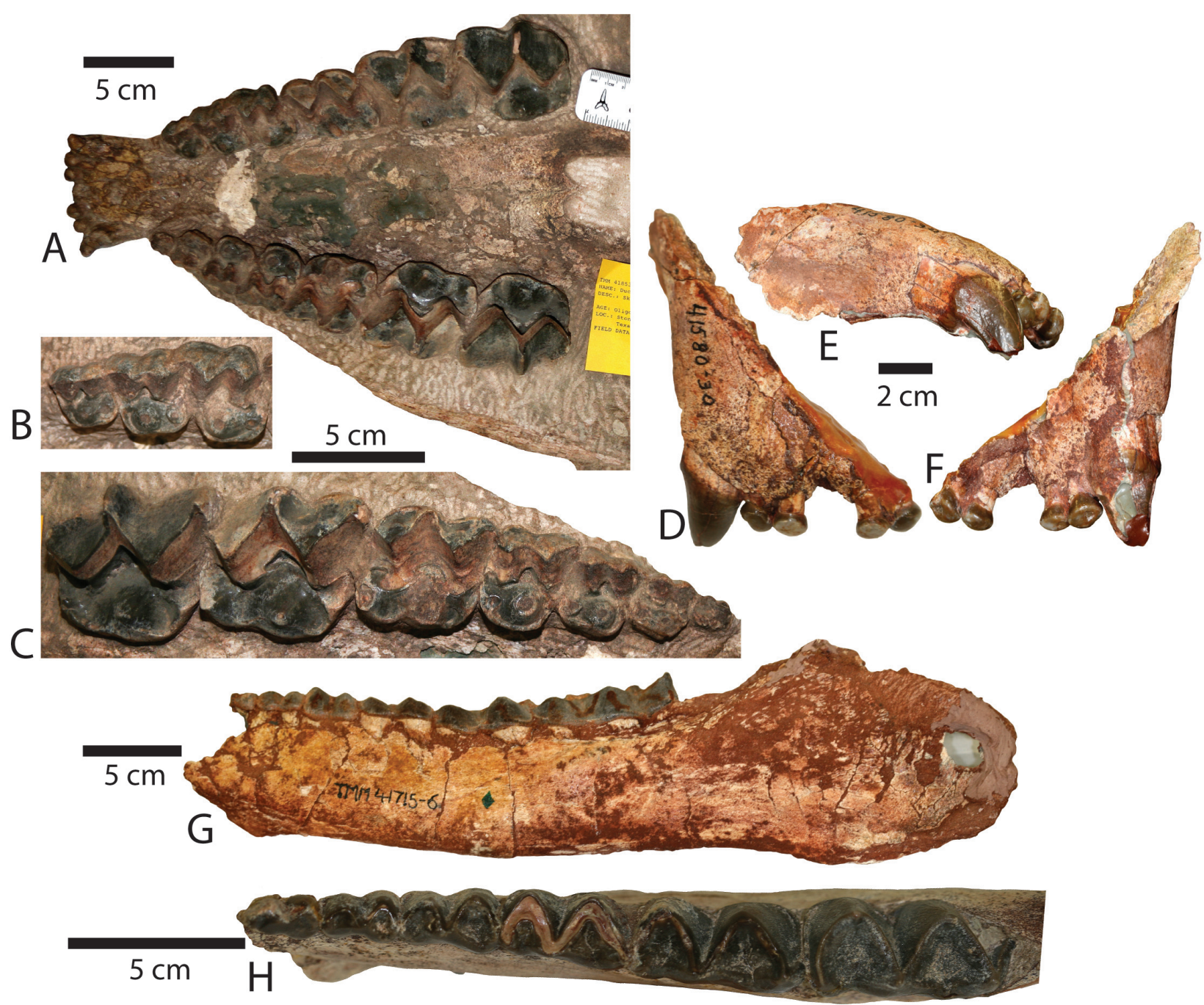

FIGURE 11. Specimens of Brontotheriita of uncertain generic and specific identify from the Skyline Channels, Devil's Graveyard Formation, Aqua Fria-Green Valley Area of Trans Pecos Texas: (A, B, C) TMM 41853-17, (D, E, F) TMM 41580-30, (G) TMM 41715-6, (H) TMM 42254-2.

talis and therefore this is not sufficient evidence to assign this material to multiple species. Therefore the fossil material from these three formations is all referred to $P$. curryi. However, in this instance, the observed variation in the position of the posterior nares happens to span the arbitrary boundary of two characters states regarding the position of the posterior nares with respect to the dentition. For that reason, this character (Character 28: position of posterior nares) was coded as a polymorphism in the phylogentic data.

Adult Protitanops curryi skulls have laterally expanded swellings on the squamosal portion of the zygomatic arches. This is a trait distinctive of advanced members of Brontotheriita, including Dianotitan, Duchesneodus, and Megacerops. The swellings are sometimes greatly expanded, and in other specimens they are less expanded. The thicknesses of these swellings are quite variable in other brontothere species as well and possibly a secondary sex trait (Mihlbachler et al., 2004). These swellings are completely absent in more basal species of Brontotheriita including Parabrontops gobiensis and Parvicornus occidentalis. Among the Eubrontotherium clarnoensis skulls from the Hancock Quarry of the Clarno Formation of Oregon, UCMP 126100 has slender zygomatic arches, while the larger more robust skull (UCMP 
TABLE 2. Character attribute differences of species of Brontotheriita. Shaded cells indicate character differences when compared to specimens referred to Protitanops curryi from the Chambers Tuff, Chisos and Prietos Formations.

\begin{tabular}{|c|c|c|c|c|c|c|c|c|c|c|c|c|c|c|}
\hline Character & 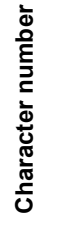 & 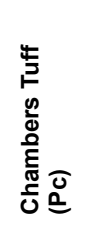 & 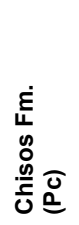 & 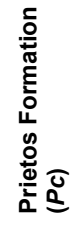 & 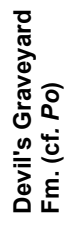 & 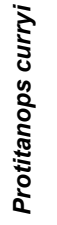 & 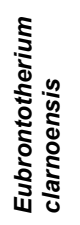 & 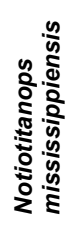 & 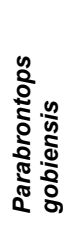 & 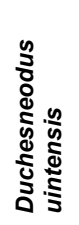 & 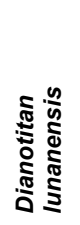 & 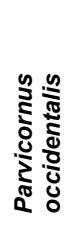 & 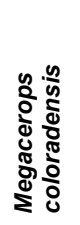 & 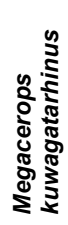 \\
\hline frontonasal horns elongate & 3 & $\mathrm{n}$ & $\mathrm{n}$ & $?$ & $?$ & $\mathrm{n}$ & $\mathrm{n}$ & $\mathrm{n}$ & $\mathrm{n}$ & $\mathrm{n}$ & $\mathrm{n}$ & $\mathrm{n}$ & $\mathrm{y}$ & y \\
\hline nasal incision extends posterior to P3 & 6 & y & y & $?$ & $?$ & y & y & $\mathrm{n}$ & y & y & $y$ & y & $\mathrm{n}$ & $\mathrm{n}$ \\
\hline anterior rim of orbit anterior to molars & 13 & $\mathrm{n}$ & $\mathrm{n}$ & $\mathrm{n}$ & $?$ & $\mathrm{n}$ & $\mathrm{n}$ & $y$ & $\mathrm{n}$ & $\mathrm{n}$ & $\mathrm{n}$ & $\mathrm{n}$ & y & $\mathrm{y}$ \\
\hline large cranial dome present & 21 & $\mathrm{n}$ & $\mathrm{n}$ & $?$ & $?$ & $\mathrm{n}$ & $\mathrm{n}$ & $?$ & $\mathrm{n}$ & y & $\mathrm{n}$ & $\mathrm{n}$ & $\mathrm{n}$ & $\mathrm{n}$ \\
\hline lateral swelling on zygomatic arch & 26 & y & y & y & $?$ & y & $\mathrm{n}$ & $?$ & $\mathrm{n}$ & y & y & $\mathrm{n}$ & y & y \\
\hline $\begin{array}{l}\text { anterior margin of posterior nares roughly } \\
\text { between M3 protocones }\end{array}$ & 28 & $\mathrm{n}$ & $\mathrm{n}$ & $\mathrm{n}$ & $\mathrm{n}$ & $\mathrm{y}$ & $\mathrm{n}$ & $\mathrm{y}$ & $\mathrm{y}$ & $\mathrm{n}$ & $\mathrm{n}$ & $\mathrm{n}$ & $\mathrm{y}$ & $\mathrm{n}$ \\
\hline emargination of posterior nares lacking & 29 & $\mathrm{n}$ & $\mathrm{n}$ & $\mathrm{n}$ & $\mathrm{n}$ & $\mathrm{n}$ & $\mathrm{n}$ & $\mathrm{n}$ & $\mathrm{n}$ & y & y & $\mathrm{n}$ & y & $\mathrm{y}$ \\
\hline Paired ventral sphenoidal fossae present & 31 & $\mathrm{n}$ & $\mathrm{n}$ & $\mathrm{n}$ & $?$ & $\mathrm{n}$ & $\mathrm{n}$ & $\mathrm{n}$ & $\mathrm{n}$ & $\mathrm{n}$ & $\mathrm{n}$ & $\mathrm{n}$ & $\mathrm{n}$ & y \\
\hline thick nuchal crest & 39 & $\mathrm{n}$ & $\mathrm{n}$ & $?$ & $?$ & $\mathrm{n}$ & $\mathrm{n}$ & $?$ & $\mathrm{n}$ & $\mathrm{n}$ & y & $\mathrm{n}$ & y & $\mathrm{n}$ \\
\hline massive occipital pillars & 40 & $\mathrm{n}$ & $\mathrm{n}$ & $?$ & $?$ & $\mathrm{n}$ & $\mathrm{n}$ & $?$ & $\mathrm{n}$ & $\mathrm{n}$ & $\mathrm{n}$ & $\mathrm{n}$ & y & y \\
\hline \# upper incisors & 42 & $?$ & 2 & $?$ & 2 & 2 & 2 & 2 & 3 & 2 & 2 & 2 & 2 & $?$ \\
\hline globular upper incisors & 44 & $?$ & y & $?$ & $\mathrm{n}$ & $y$ & y & $\mathrm{y}$ & $\mathrm{y}$ & $\mathrm{y}$ & $\mathrm{y}$ & $\mathrm{n}$ & $y$ & $?$ \\
\hline incisor row arched & 45 & $\mathrm{n}$ & $\mathrm{n}$ & $?$ & $\mathrm{y}$ & $\mathrm{n}$ & $\mathrm{n}$ & $\mathrm{n}$ & $\mathrm{n}$ & $\mathrm{n}$ & $\mathrm{n}$ & y & $\mathrm{n}$ & $?$ \\
\hline upper postcanine diastema & 46 & $y$ & y & $?$ & $y$ & y & y & y & y & $\mathrm{n}$ & $\mathrm{n}$ & y & $\mathrm{n}$ & $\mathrm{n}$ \\
\hline P2 preprotocrista strong & 51 & $?$ & y & $\mathrm{y}$ & $\mathrm{y}$ & $y$ & $\mathrm{y}$ & y & $\mathrm{n}$ & y & $y$ & $y$ & $y$ & $\mathrm{y}$ \\
\hline molar metaloph present & 67 & $\mathrm{n}$ & $\mathrm{n}$ & $\mathrm{n}$ & $\mathrm{n}$ & $\mathrm{n}$ & $\mathrm{n}$ & $\mathrm{n}$ & $\mathrm{n}$ & $\mathrm{n}$ & $\mathrm{n}$ & $\mathrm{n}$ & $\mathrm{n}$ & y \\
\hline M3 hypocone present & 69 & $y$ & y & y & y & $y$ & $y / n$ & y & y & $y$ & y & $y / n$ & $y$ & y \\
\hline $\begin{array}{l}\text { mandibular symphysis posterior to } \mathrm{P} 4 \\
\text { trigonid }\end{array}$ & 71 & $\mathrm{y}$ & $?$ & $?$ & $\mathrm{n}$ & $y$ & $\mathrm{y}$ & y & $?$ & $y$ & $?$ & $\mathrm{n}$ & $y$ & $?$ \\
\hline \# lower incisors & 72 & 3 & $?$ & $?$ & $?$ & $?$ & 3 & $?$ & $?$ & 3 & $?$ & 3 & 2 & $?$ \\
\hline mandibular postcanine diastema & 76 & $y$ & $?$ & $?$ & $?$ & y & y & $?$ & $?$ & y & $?$ & y & $\mathrm{n}$ & $?$ \\
\hline p3 metaconid present & 82 & $?$ & $?$ & $?$ & $?$ & $?$ & $\mathrm{n}$ & y & $?$ & $y$ & $?$ & $y / n$ & y & $?$ \\
\hline horn broadest in antero-posterior direction & 90 & y & y & $?$ & $?$ & y & $y / n$ & $?$ & y & $y / n$ & $y / n$ & y & $\mathrm{n}$ & $\mathrm{n}$ \\
\hline antero-lingual upper premolar cusp present & 93 & $\mathrm{n}$ & $\mathrm{n}$ & $\mathrm{n}$ & $\mathrm{n}$ & $\mathrm{n}$ & $\mathrm{n}$ & $\mathrm{n}$ & $\mathrm{n}$ & $y$ & $\mathrm{n}$ & $\mathrm{n}$ & $y / n$ & $y / n$ \\
\hline bifurcated horns & - & $\mathrm{n}$ & $\mathrm{n}$ & $?$ & $?$ & $\mathrm{n}$ & $\mathrm{n}$ & $\mathrm{n}$ & $\mathrm{n}$ & $\mathrm{n}$ & $\mathrm{n}$ & $n$ & $\mathrm{n}$ & y \\
\hline
\end{tabular}

126101) has zygomatic arches that are simply thickened throughout their whole length but both skulls lack discrete swellings at the midpoint of the zygomatic arch. The presence of these zygomatic swellings on the $P$. curryi specimens and lack of such structures in E. clarnoensis is likely a taxonomically meaningful difference with which these species can be separated. The zygomatic arches of the type and only known specimen of Notiotitanops mississippiensis (USNM 16646) are not preserved. This specimen has a more anteriorly positioned orbit and an anteroposteriorly shorter lateral nasal incision. In these respects, N. mississippiensis resembles the more advanced genus
Megacerops. Therefore, although N. mississippiensis is the most poorly known member of Brontotheriita, it seems to be distinct from Protitanops curryi. Other species of Brontotheriita are more readily differentiated from $P$. curryi based on greater numbers of character differences (Table 2).

Various specimens referred to Teleodus californicus from the Duchesnean Sespe Formation of California Stock (1935), considered nomina dubia by Mihlbachler (2008), might be conspecific with Protitanops curryi, but due to the limited nature of the existing fossil material their specific identity remains enigmatic. 


\section{Taxonomic Status of Menodus bakeri}

Stovall (1948) based Menodus bakeri on a lower jaw, about 12 vertebrae, several ribs, a partial femur, and a few foot and toe bones from the Chambers Tuff of the Vieja area. Stovall did not designate a holotype specimen, but Wilson (1977a) considered OU 18-4-S17 (a left mandibular ramus with c, p2-p3, p4 (partial) m1-m3; plate I, figure 7 in Stovall, 1948) to be the type of Menodus bakeri. Other specimens described include a portion of juvenile maxillary with right $\mathrm{dP} 2, \mathrm{dP} 3, \mathrm{dP} 4$ (OU 19-2-S8; plate I, figure 8 in Stovall, 1948) that were mistakenly identified as adult molars and attributed to an "unidentified titanothere," and a p2 and p3 (OU 19-2-S8; plate I, figure 9 in Stovall, 1948). Stovall may have intended to name a second species based on these specimens (Wilson, 1977a). The p2 and p3 were referred to "Microdonta. bendi" in plate I, figure 9 of Stovall (1948), but the name does not otherwise appear in that paper. Wilson (1977a) considers " $M$. bendi" a nomen nudum, and it is not considered further here.

Wilson (1977a) referred additional material to Menodus bakeri from the Vieja Area, including a skull (TMM 40840-39), lower jaw (TMM 40840-38), an articulated right forelimb (TMM 40804-1), and deciduous upper premolars (TMM 40209) all from the early Chadronian upper part of the Chambers Tuff, Little Egypt Local fauna. Wilson (1977a) questionably referred another skull (TMM 40932-1) from the middle part of the Chisos Formation to M. bakeri. Wilson (1977a) also referred the entire collection in the Field Museum (FMNH PM) from the lower part of the Chambers Tuff to $M$. bakeri, although he did not figure or describe any of this material. Wilson (1977b) referred this same material to Teleodus sp., although that genus is no longer available as a valid name because its type species, $T$. avus Marsh 1890, is a paleontological hoax (Lucas, 2004).

The original assignment of M. bakeri to Menodus was based on lower molar row length of the type specimen $(\mathrm{m} 1-\mathrm{m} 3$ length $=192 \mathrm{~mm})$ and was differentiated from other species of Menodus by the absence of cingulum on all teeth except the last molar and forward projecting canines (Stovall, 1948). At the time, Stovall would have drawn from Osborn's (1929) concept of Menodus and other late Eocene brontothere genera that are now all considered synonyms of Megacerops. Menodus is currently considered an invalid genus. The type species of Menodus, M. giganteus Pomel (1849) is the first brontothere fossil ever to be described.
Although $M$. giganteus is the oldest taxonomic name available for a brontothere, the type specimen consists of a large jaw fragment with partial molars (USNM 21820) and lacks sufficient character data to diagnose a unique species (Mihlbachler et al., 2004).

Wilson's (1977a) observations on the procumbent nature of the lower canines of the type of Menodus bakeri have dubious taxonomic significance. Although the lower canine of the holotype is preserved, the anterior end of the mandible, including the portion of the mandible that would have contained the canine alveolus, is incomplete. The orientation of the lower canine is suspect, but as reconstructed (Wilson, 1977a, Figure 4) is not unusual when compared to other advanced brontotheres. The molar cingulids of brontotheres, also used by (Stovall, 1948) to differentiate M. bakeri, are commonly weak, discontinuous and unevenly distributed (Mihlbachler, 2007b, 2008; Mihlbachler and Deméré, 2009) and do not have strong value for species diagnoses. Cingulids are often worn away in more anterior molars, which are more heavily worn. Lucas and Schoch (1989) synonomized Menodus bakeri (in part) with Duchesneodus uintensis, however, the single $M$. bakeri specimen (TMM 40062) they referred to Duchesneodus uintensis is also a jaw lacking diagnostic characters, therefore their taxonomic revision is not supported.

There are two well-represented species of brontothere preserved in the Chambers Tuff that can be identified from complete skulls with diagnostic characters preserved, Duchesneodus uintensis and Protitanops curryi. There are only two mandibles of $D$. uintensis from the Duchesneodus quarry from the LaPoint Member of the Duchesne River Formation in Duchesne County, Utah. These have molar row lengths $(131 \mathrm{~mm}$ and $165 \mathrm{~mm}$ ) that are considerably less than the type of Menodus bakeri, which has a lower molar row length of 193 $\mathrm{mm}$ as reported by Stovall (1948). The sample of skulls from the same Duchesneodus quarry in Utah is considerably larger $(\mathrm{N}=8)$. Upper molar row lengths in this sample have a mean or $167 \mathrm{~mm}$ with a standard deviation of 15.3) (see Mihlbachler 2008 for data and summary statistics for $D$. uintensis) and the lower molar length of the type of Menodus bakeri is well above one standard deviation. The molar row length of the type of $M$. bakeri is similar to the type specimen of $P$. curryi $(190 \mathrm{~mm})$, but below the lower standard deviation of the molar row length among specimens referred to Protitanops curryi from Texas (see m1-m3 mesiodistal 
length in Table 1). Because of these uncertainties Menodus bakeri is a nomen dubium. However, it is more likely to be a synonym of the larger species, Protitanops curryi.

\section{Size Comparisons}

Some species of brontotheres are exceptionally large, and there are also numerous cases of dwarfism within Brontotheriidae (Miao, 1982; Qi and Beard, 1996, 1998; Mihlbachler and Samuels, 2016). Nonetheless, due to the size similarities of many species, size is not always useful for identification or diagnosis of brontothere species (Mihlbachler, 2008). The potential for geographic size variation and the liklihood that some species, particularly among the horned brontotheres, may have been characterized by significant sexual size dimorphism add further complications to differentiating species size based on statistically limited samples (Mihlbachler, 2011). Nonetheless, size and size variation are important biological attributes of species and should be considered.

Species of Brontotheriita known from samples appropriate for quantifying size variation include Parvicornus occidentalis, Eubrontotherium clarnoensis, and Duchesneodus uintensis, whose cranial length and molar row lengths are summarized in Figure 12 along with the specimen attributed to Protitanops curryi. Among these taxa, P. occidentalis and $D$. uintensis are the smallest species while $E$. clarnoensis and $P$. curryi form a cluster of larger species. Notiotitanops mississippiensis and Dianotitan lunanensis, whose data are derived from only a single specimen each, fall in the size ranges of the smaller species, while Parabrontops gobiensis, also known from a more limited amount of material seems closer in size to $E$. clarnoensis.

Individual measurements of the Protitanops curryi material from the Chisos Formation and Vieja-Ojinaga Area are provided in Appendix 3. The ranges of values from each of the fossil areas overlap for many variables. When the $P$. curryi specimens are combined into a single set of summary statistics (Table 1) the total extent of size variation does not appear to exceed what has been observed in other species of brontotheres. Coefficients of variation (CVs) for craniodental measurements in this combined sample range from 2-39. This range of variation is not different from the range of $\mathrm{CVs}$ of the same measurements for other brontothere species (Mihlbachler et al., 2004; Mihlbachler, 2008; 2011; Mihlbachler and Deméré, 2009, 2010). The highest CVs, ranging from 11-39, are for dimensions of the frontonasal horn, thick- ness of the zygomatic arch, and diameters of the upper and lower canines. Other brontotheres have similarly high CVs associated with the same traits and are postulated to have been secondary sex characters (Mihlbachler et al., 2004; Mihlbachler, 2011). The CVs for the remaining dimensions, consisting of skull length and various postcanine tooth and tooth-row dimensions range between 2-10 and are similar to CVs reported for the same traits in other brontothere species. Other large-bodied perissodactyls show similar size distributions with high CVs among features postulated to have been sexually dimorphic (tusks, horn bosses) and much lower CVs among other cranio-dental characters (Mihlbachler, 2007a).

The skull length of the type specimen of Protitanops curryi (LACM/CIT 1854) from California of the type is at the upper range of the species (Table 1). However, the cheek teeth of the type specimen seem proportionately small in comparison to the Texas material. The mesiodistal length of the upper molar row is below one standard deviation and the premolar row is less than the two standard deviations below the means of these same variables among the Texas specimens. Other dimensions of the type from Table 1 fall within one standard deviation of the means of the Texas specimens. The other less complete specimen (LACM/CIT 2007, Figure $3 \mathrm{~B}$ ) from the Titus Canyon Formation that may also belong to $P$. curryi has dental dimensions that are near the upper margin of $P$. curryi with one dimension (M2 mesiodistal length) falling two standard deviations above the mean of the same value in the Texas specimens.

Brontothere specimens with heavily worn dentitions exhibit striking amounts of interstitial wear (attritional between adjacent teeth) leading to considerable mesio-distal shortening of the toothrow with age (Wood, 1938). All of the specimens here, except for the ontogenetically youngest ones, exhibit differing amounts of interstitial wear. Consequently, without larger samples, it is difficult to make rigorous statistical comparisons of dental row lengths. Many of the dimensions of the individual teeth of the Titus Canyon type skull (LACM/CIT 1854) including transverse widths, which are not effected by interstitial wear, overlap with the ranges seen in the Texas sample while most of the individual tooth measurements of the other Titus Canyon specimen (LACM/CIT 2007) are beyond the range observed in the Texas sample (Appendix 3).

In conclusion from these metric comparisons, the available data on size are insufficient to tease apart subtle differences in size and proportions 
PALAEO-ELECTRONICA.ORG
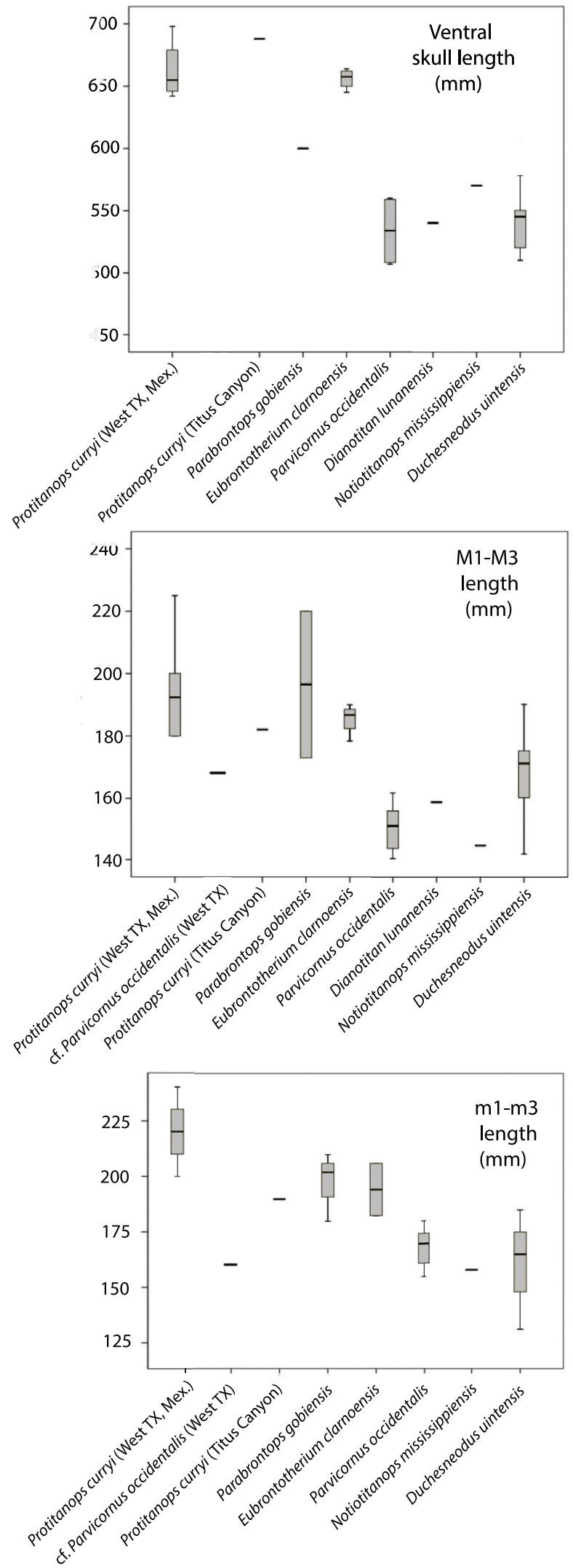

FIGURE 12. Size distributions for ventral skull length, upper molar row length, and lower molar row length for Protitanops curryi and closely related brontotheriids. 
between the various samples referred to $P$. curryi. The Texas and California samples referred to Protitanops curryi exhibit a total range of size variation and yield coefficients of variation that do not exceed that observed in other species of brontotheres. None of these data offer evidence contradicting the character-based assignment of these specimens to a single species.

The limited quantity of more fragmentary specimens from the Devil's Graveyard Formation referred to cf. Parvicornus occidentalis prohibits statistical size comparisons. This fossil material appears to represent individuals that are smaller than the known size range of the Texas material referred to Protitanops curryi material. Character evidence described above suggests that Parvicornus occidentalis is the better species candidate for this fossil material. The upper molar row length (M1-M3) of c.f. Parvicornus occidentalis (from specimen (TMM 41863-17) is larger than known specimens of $P$, occidentalis, while the lower molar row length (from another specimen (TMM41715-6) is below average for the species (Figure 12). Unfortunately, size data are not sufficient evidence for species assignment. At best, the existing evidence on size does not offer evidence that contradicts the provisional assignment of this material to cf. Parvicornus occidentalis.

\section{Biostratigraphy and Biogeography}

The Trans-Pecos region of West Texas is the only place in North America where the middle-late Eocene is recorded by superimposed mammalian faunas that have been dated radiometrically and with magnetic stratigraphy (Prothero, 1996), and this area therefore provides the most complete picture of the transition from Uintan, Duchesnean, and Chadronian land mammal ages and faunas. Although represented by abundant material, the brontotheres from this region have, until now, remained poorly understood. The earliest brontothere in this sequence, Protitanotherium emarginatum (=Sthenodectes australis), is known from numerous complete skulls in the lower Member of the Devil's Graveyard Formation in the Aqua Fria Area of Brewster County (Wilson, 1977a; Mihlbachler, 2008, 2011). Complete skulls referred to $P$. emarginatum occur in the lower Whistler Squat Local fauna (Boneanza locality, TMM 41747-106) and the higher Serendipity local fauna (Titanothere Channels locality, TMM 41723-3 and TMM 417236 ). The Whistler Squat and Serendipity local faunas have been faunally correlated to the Wagonhound (Ui2, Uinta B) and Myton (Ui3, Uinta C)
Members of the Uinta Formation of Utah (Wilson, 1986; Prothero, 1996; Robinson et al., 2004), but the presence of $P$. emarginatum in both the Whistler Squat and Serendipity local faunas suggests stronger affiliations with the late Uintan fauna of the Myton Member, where $P$. emarginatum also occurs. Other brontotheres that occur in the Myton Member of the Uinta Formation, Metatelmatherium ultimum and Diplacodon elatus, have not been identified in the southwest.

Although many Duchesnean brontothere fossils have previously been assigned to Duchesneodus (Lucas and Schoch, 1982, 1989; Lucas, 2004), much of the material is fragmentary and lacks sufficient character evidence to be truly identifiable. The only Duchesneodus species is $D$. uintensis, and it can be identified from diagnosable material in the Duchesne River Formation of Utah, Galisteo Formation of New Mexico, and Vieja-Ojinaga Area of Texas. Duchesneodus is known only from the Duchesnean land mammal age. The Texas record of $D$. uintensis is presently confined to the late Duchesnean Blue Cliff Horizon of the lower part of the Chambers Tuff.

Parvicornus occidentalis is another Duchesnean brontothere, presently known only from numerous complete skulls, mandibles, and postcranials from the Santiago Formation of San Diego County California. The species has not been identified elsewhere, although there are numerous possible occurrences elsewhere. In addition to the early Duchesnean cf. P. occidentalis material from the Skyline Channels portion of the Devil's Graveyard Formation in West Texas, material from the Duchesnean Slim Buttes Formation of South Dakota previously assigned to a nomen dubium, Teleodus thyboi (Bjork, 1967), have also been referred to cf. Parvicornus occidentalis (Mihlbachler and Deméré, 2009). Stock (1938) referred another specimen (LACM/CIT 2143) from the Sespe Formation of Simi Valley California to the nomen dubium Duchesneodus californicus (Stock, $1935)$ that is also better identified as cf. P. occidentalis.

Previously, Protitanops curryi was known only from the early Chadronian Titus Canyon Formation of California. Its occurrence in the Chambers Tuff Formation in both the Porvenir and Little Egypt faunas and in the Rancho Gaitan local fauna of the Prietos Formation of Mexico spans the late Duchesnean and early Chadronian. There are a few other records of Chadronian-aged brontothere specimens from the Big Sand Draw Sandstone Lentil of the White River Formation at Beaver 
Divide in Fremont County, Wyoming (Mihlbachler et al., 2004), and the Chadronian Antero Formation, in South Park, Colorado (Sweedler et al., 2021) that could also represent Protitanops curryi, but these identifications are tentative due to the incomplete nature of the material. Finally, Megacerops, the last brontothere in North America, appears to be confined to the Chadronian land mammal age and is known predominantly from Chadronian layers of the White River Group of the Great Plains, and the Cypress Hills Formation of Saskatchewan.

Finally, there is an uncatalogued skull in the PIN collections from the Khoer Dzan locality, Ergilin Dzo Formation of Southern Mongolia of late Eocene age (Meng and McKenna, 1998; Tsubamoto et al., 2011) that is very similar to Protitanops curryi. More detailed analysis of the partly unstudied PIN collections of brontotheres is needed. However, if $P$. curryi were identified in Asia it would not be unprecedented. Other North Ameri- can species, Metatelmatherium ultimum and Eubrontotherium clarnoensis have been identified in Asia (Mihlbachler, 2008). Cladistically derived phylogenetic analyses of Brontotheriita suggest many sister taxon relationships between Asian and North American taxa, and that numerous intercontinental dispersals occurred within this clade throughout the Eocene.

\section{ACKNOWLEDGEMENTS}

I thank D. Ruez Jr. and E. Lundelius for hosting my visit to the TMM vertebrate paleontology collections years ago and assistance with the collections (MCM). Matthew Brown provided more recent assistance with TMM collections and data. Bill Simpson offered invaluable help locating, moving, and photographing specimens at the FMNH. Support for this research was provided in part by the New York Institute of Technology College of Osteopathic Medicine.

\section{REFERENCES}

Averianov, A., Danilov, I., Chen, W., and Jin, J. 2018. A new brontothere from the Eocene of South China. Acta Palaeontologica Polonica, 63:189-196. https://doi.org/10.4202/app.00431.2017

Bjork, P.R. 1967. Latest Eocene vertebrates from Northwestern South Dakota. Journal of Paleontology, 41:227-236. https://www.jstor.org/stable/i255769

Chow, M. and Hu, C.C. 1959. A new species of Parabrontops from the Oligocene of Lunan, Yunnan. Ku sheng wu hs ueh pao (Acta Palaeonntologica Sinica), 7:85-88.

Chow, M., Yu-Ping, C., and Su-Yin, T. 1974. Some early Tertiary Perissodactyla from Lunan Basin, E. Yunnan. Vertebrata PalAsiatica, 12:262-273.

Clark, J. 1937. The stratigraphy and paleontology of the Chadron Formation in the Big Badlands of South Dakota. Annals of the Carnegie Museum, 25:261-251.

Coombs, M.C. 1975. Sexual dimorphism in the chalicotheres (Mammalia, Perissodactyla). Systematic Zoology, 24:55-62. https://doi.org/10.2307/2412697

Cope, E.D. 1880. The Bad Lands of the Wind River and their Fauna. American Naturalist, 14:745-748.

Ferrusquía-Villifranca, I. 1967. Rancho Gaitan local fauna, early Chadronian, northeastern Chihuahua. Boletín de la Sociedad Geológica Mexicana, 99-138. https://doi.org/10.18268/bsgm1967v30n2a1

Ferrusquía-Villafranca, I. 1984. A review of the early and middle Tertiary mammal faunas of Mexico. Journal of Vertebrate Paleontology, 4:187-198. https://doi.org/10.1080/ 02724634.1984.10012002

Froehlich, D.J. 2002. Quo vadis eohippus? The systematics and taxonomy of the early Eocene equids (Perissodactyla). Zoological Journal of the Linnean Society, 134:141-256. https://doi.org/10.1046/j.1096-3642.2002.00005.x

Gazin, C.L. and Sullivan, J.M. 1942. A new titanothere from the Eocene of Mississippi with notes on the correlation between the marine Eocene of the Gulf Coastal Plain and continental Eocene of the Rocky Mountain region. Smithsonian Miscellaneous Collections, 101 (13) 3679:1-13. 
Goloboff, P.A., Carpenter, J.M., Arias, J.S., and Esquivel, D.R.M. 2008. Weighting against homoplasy improves phylogenetic analysis of morphological data sets. Cladistics, 24:758773. https://doi.org/10.1111/j.1096-0031.2008.00209.x

Gregory, W.K. and Cook, H.J. 1928. New material for the study of evolution: a series of primitive rhinoceros skulls (Trigonias) from the lower Oligocene of Colorado. Proceedings of the Colorado Museum of Natural History, 8:1-32.

Gunnell, G.F. and Yarborough, V.L. 2000. Brontotheriidae (Perissodactyla) from the late early and middle Eocene (Bridgerian), Wasatch and Bridger Formations, southern Green River Basin, southwestern Wyoming. Journal of Vertebrate Paleontology, 20:349-368. https://doi.org/10.1671/0272-4634(2000)020[0349:BPFTLE]2.0.CO;2

Hatcher, J.B. 1895. On a new species of Diplacodon, with a discussion of the relations of that genus to Telmatotherium. American Naturalist, 29:1084-1090.

Lambe, L.M. 1908. Part 4: The vertebrata of the Oligocene of the Cypress Hills, Saskatchewan. Contributions to Canadian Paleontology, 3:1-64. https://doi.org/10.5962/bhl.title.64818

Leidy, J. 1870. (Description of a new genus and species, Megacerops coloradensis). Proceedings of the Academy of Natural Sciences of Philadelphia, 1-2.

Li, S. 2018. A new species of Brontotheriidae from the Middle Eocene of Junggar Basin, Xinjiang, China. Vertebrata PalAsiatica, 56:25-44. https://doi.org/10.19615/j.cnki.1000-3118.170314

Lucas, S.G. 2004. O.C. Marsh and the Eocene Brontothere Teleodus: a paleontological hoax, p. 119-127. In Lucas, S.G., Zeigler, K.E., and Kondrashov, P.E. (eds.), Paleogene Mammals. New Mexico Museum of Natural History and Science Bulletin 26.

Lucas, S.G. and Schoch, R.M. 1982. Duchesneodus, a new name for some titanotheres (Perissodactyla, Brontotheriidae) from the late Eocene of western North America. Journal of Paleontology, 56:1018-1023.

Lucas, S.G. and Schoch, R.M. 1989. Taxonomy of Duchesneodus (Brontotheriidae) from the late Eocene of North America, p. 490-503. In Prothero, D.R. and Schoch, R.M. (eds.), The Evolution of the Perissodactyls. Oxford University Press, New York.

Mader, B.J. 1989. The Brontotheriidae: A systematic revision and preliminary phylogeny of North American genera, p. 458-484. In Prothero, D.R. and Schoch, R.M. (eds.), The Evolution of Perissodactyls. Oxford University Press, New York.

Mader, B.J. 1998. Brontotheriidae, p. 525-536. In Janis, C.M., Scott, K.M., and Jacobs, L.L. (eds.), Evolution of Tertiary Mammals of North America: Volume I: Terrestrial Carnivores, Ungulates, and Ungulate-like Mammals. Cambridge University Press, Cambridge. https://doi.org/10.1017/cbo9780511541438

Mader, B.J. 2009. A species-level revision of the North American brontotheres Eotitanops and Palaeosyops (Mammalia, Perissodactyla). Zootaxa, 2339:1-43. https://doi.org/10.11646/zootaxa.2339.1.1

Mader, B.J. and Alexander, J.P. 1995. Megacerops kuwagatarhinus n. sp., an unusual brontothere (Mammalia, Perissodactyla) with distally forked horns. Journal of Paleontology, 69:581-587. https://doi.org/10.1017/S0022336000034958

Marsh, O.C. 1890. Notice of new Tertiary mammals. American Journal of Science, 39: 523-525.

Meng, J. and McKenna, M.C. 1998. Faunal turnovers of Palaeogene mammals from the Mongolian Plateau. Nature, 394:364-367. https://doi.org/10.1038/28603

Miao, D. 1982. Early Tertiary fossil mammals from the Shinao basin, Panxian County, Guizhou Province. Acta Palaeontologica Sinica, 21:527-536.

Mihlbachler, M.C. 2005. Linking sexual dimorphism and sociality in rhinoceroses: insights from Teleoceras proterum and Aphelops malacorhinus from the late Miocene of Florida. Bulletin of the Florida Museum of Natural History, 45:495-520. https://doi.org/10.1666/0094-8373(2003)029<0412:dolmrt>2.0.co;2

Mihlbachler, M.C. 2007a. Sexual dimorphism and mortality bias in a small Miocene North American Rhino, Menoceras arikarense: insights into the coevolution of sexual dimorphism and sociality in rhinos. Journal of Mammalian Evolution, 14:217-238. https://doi.org/10.1007/s10914-007-9048-4

Mihlbachler, M.C. 2007b. Eubrontotherium clarnoensis, a new genus and species of brontothere (Brontotheriidae, Perissodactyla) from the Hancock Quarry, Clarno Formation, Wheeler County, Oregon. Paleobios, 21:19-39. 
Mihlbachler, M.C. 2008. Species taxonomy, phylogeny, and biogeography of the Brontotheriidae (Mammalia: Perissodactyla). Bulletin of The American Museum of Natural History, 311:1475. https://doi.org/10.1206/0003-0090(2008)501[1:STPABO]2.0.CO;2

Mihlbachler, M.C. 2011. A new Uintan horned brontothere from Wyoming and the evolution of canine size and sexual dimorphism in the Brontotheriidae (Perissodactyla: Mammalia). Journal of Vertebrate Paleontology, 31:202-214. https://doi.org/10.1080/02724634.2011.539653

Mihlbachler, M.C. and Deméré, T.A. 2009. A new species of Brontotheriidae (Perissodactyla, Mammalia) from the Santiago Formation (Duchesnean, Middle Eocene) of Southern California. Proceedings of the San Diego Society of Natural History, 41:1-36.

Mihlbachler, M.C. and Deméré, T.A. 2010. Phylogenetic status of Metarhinus pater (Brontotheriidae; Perissodactyla) from southern California and species variation in Metarhinus from the middle Eocene of North America. Journal of Vertebrate Paleontology, 30:1229-1244. https://doi.org/10.1080/02724634.2010.483568

Mihlbachler, M.C., Lucas, S.G., and Emry, R.J. 2004a. The holotype specimen of Menodus giganteus, and the "insoluble" problem of Chadronian brontothere taxonomy, p. 129-135. In Lucas, S.G., Zeigler, K.E., and Kondrashov, P.E. (eds.), Paleogene Mammals. New Mexico Museum of Natural History and Science Bulletin 26.

Mihlbachler, M.C., Lucas, S.G., and Emry, R.J. 2004b. Late Eocene brontotheres (Mammalia, Perissodacyla) from Beaver Divide, Wyoming, and their biochronological significance, $p$. 113-1118. In Lucas, S.G., Zeigler, K.E., and Kondrashov, P.E. (eds.), Paleogene Mammals. New Mexico Museum of Natural History and Science Bulletin 26.

Mihlbachler, M.C. and Samuels, J.X. 2016. A small-bodied species of Brontotheriidae from the middle Eocene Nut Beds of the Clarno Formation, John Day Basin, Oregon. Journal of Paleontology, 90:1233-1244. https://doi.org/10.1017/jpa.2016.61

Nikolov, V.I. and Heissig, K. 1985. Fossile Saugertiere aus dem Obereozan und Unteroligozan Bulgariens und Bedeuntung fur die Palaeogeographie. Mitteilungen der Bayerischen Staatssammlung für Paläontologie und Histor. Geologie, 25:61-79.

Osborn, H.F. 1925. Upper Eocene and Lower Oligocene titanotheres of Mongolia. American Museum Novitates, 202:1-12.

Osborn, H.F. 1929. Titanotheres of Ancient Wyoming, Dakota, and Nebraska. United States Geological Survey Monographs, 55:1-894. https://doi.org/10.5962/bhl.title.36431

Peterson, O.A. 1931. New species of the genus Teleodus from the Upper Uinta of Northeastern Utah. Annals of the Carnegie Museum, 20:307-312.

Pilgrim, G.E. 1925. The Perissodactyla of the Eocene of Burma. Memoirs of the Geological Survey of India, Paleontologia Indica, 8:1-28.

Pilgrim, G.E. and Cotter, G. de P. 1916. Some newly discovered Eocene mammals from Burma. Records of the Geological Survey of India, 47:42-77.

Pomel, A. 1849. Description d'un os maxillaire fossile de Palaeotherium par Hiram Prout. Bibliothèque Universelle de Genève. Archives des Sciences Physiques et Naturelles. Vol 10, pp. 73-75.

Prothero, D.R. 1996. Magnetostratigraphy of the Eocene-Oligocene Transition in Trans-Pecos Texas, p. 189-198. The Terrestrial Eocene-Oligocene Transition in North America. In Prothero, D.R. and Emry, R.J. (eds.), Cambridge University Press. https://doi.org/10.1017/cbo9780511665431.010

Prothero, D.R. and Schoch, R.M. 2002. Horns, Tusks, and Flippers: The Evolution of Hoofed Mammals. Johns Hopkins, Baltimore. https://doi.org/10.1578/am.33.2.2007.254

Prothero, D.R. and Emry, R.J. 2004. The Chadronian, Orellan, and Whitneyan North American land mammal ages, pp. 156-168 In Woodburne, M.O. (ed.), Late Cretaceous and Cenozoic Mammals of North America. Columbia University Press, New York. https://doi.org/10.7312/wood13040-007

Qi, T. and Beard, K.C. 1996. Nanotitan shanghuangensis, gen. et sp. nov.: The smallest known brontothere. Journal of Vertebrate Paleontology, 16:578-581. https://doi.org/10.1080/02724634.1996.10011342

Qi, T. and Beard, K.C. 1998. Nanotitanops, a new name for Nanotitan Qi and Beard, 1996 not Nanotitan Sharov, 1968. Journal of Vertebrate Paleontology, 18:812. https://doi.org/10.1080/02724634.1998.10011109 
Robinson, P., Gunnell, G.F., Walsh, S.L., Clyde, W.C., Storer, J.E., Stucky, R.K., Froehlich, D.J., Ferrusquia-Villafranca, I., and McKenna, M.C. 2004. Wasatchian through Duchesnean biochronology, p. 106-155. In Woodburne, M.O. (ed.), Late Cretaceous and Cenozoic Mammals of North America. Columbia University Press, New York. https://doi.org/10.7312/wood13040

Russell, D.E. and Zhai, R. 1987. The Paleogene of Asia: mammals and stratigraphy. Memoires du Museum National D'Histoire Naturelle, Sciences de la Terre, 52:1-488.

Russell, L.S. 1940. Titanotheres from the lower Oligocene Cypress Hills Formation of Saskatchewan. Transactions of the Royal Society of Canada, 34:89-100.

Savage, D.E., Russell, D.E., and Louis, P. 1965. European Eocene Equidae. University of California Publications in Geological Sciences, 56:1-94.

Schiebout, J.A., Rigsby, C.A., Rapp, S.D., Hartnell, J.A., and Standhardt, B.R. 1987. Stratigraphy of the Cretaceous-Tertiary and Paleocene-Eocene Transition Rocks of Big Bend National Park, Texas. The Journal of Geology, 95:359-375. https://doi.org/10.1086/629135.

Scott, W.B. 1945. The Mammalia of the Duchesne River Oligocene. Transactions of the American Philosophical Society, 34:209-253. https://doi.org/10.2307/1005542

Scott, W.B. and Jepson, G.L. 1941. The Mammalian fauna of the White River Oligocene. Part 5. Perissodactyla. Transactions of the American Philosophical Society, 28:747-980.

Sites, J.W. and Marshall, J.C. 2004. Operational criteria for delimiting species. Annual Review of Ecology and Systematics, 35:199-227. https://doi.org/10.1146/annurev.ecolsys.35.112202.130128

Stock, C. 1935. Titanothere remains from the Sespe of California. Proceedings of the National Academy of Sciences, 21:456-462. https://doi.org/10.1073/pnas.21.7.456

Stock, C. 1936. Titanotheres from the Titus Canyon Formation, California. Proceedings of the National Academy of Sciences, 22:656-661.

Stock, C. 1938. A titanothere from the type Sespe of California. Proceedings of the National Academy of Sciences, 24:507-512. https://doi.org/10.1073/pnas.24.11.507

Stovall, J.W. 1948. Chadron vertebrate fossils from below the Rim Rock of Presidio County, Texas. American Journal of Science, 246:78-95. https://doi.org/10.2475/ajs.246.2.78

Sweedler, R.E., Eberle, J.J., and Mihlbachler, M.C. 2021. A latest Eocene (Chadronian) brontothere (Mammalia, Perissodactyla) from the Antero Formation, South Park, Colorado. Rocky Mountain Geology, 56:37-50. https://doi.org/10.24872/rmgjournal.56.1.37

Swofford, D.L. 2003. PAUP*. Phylogenetic Analysis Using Parsimony (*and Other Methods). Version 4. Sinauer Associates, Sunderland, Massachusetts. https://doi.org/10.1007/978-1-4020-6754-9_12413

Testarmata, M.M. and Gose, W.A. 1979. Magnetostratigraphy of the Eocene-Oligocene Vieja Group, Trans-Pecos Texas, p. 55-66. In Walton A.W and Henry C.D. (eds.) Cenozoic Geology of the Trans-Pecos Volcanic Field of Texas. Bureau of Economic Geology Guidebook 19. Bureau of Economic Geology of the University of Texas, Austin.

Tokaryk, T. 1985. A historical review of the Brontotheriidae collected in Saskatchewan. Blue Jay, 43:151-154.

Tsubamoto, T., Saneyoshi, M., Watabe, M., Tsogtbaatar, K., and Mainbayar, B. 2011. The Entelodontid Artiodactyl fauna from the Eocene Ergilin Dzo Formation of Mongolia with comments on Brachyhyops and the Khoer Dzan Locality. Paleontological Research, 15:258268. https://doi.org/10.2517/1342-8144-15.4.258.

Turner, K.J., Berry, M.E., Page, W.R., Lehman, T.M., Bohannon, R.G., Scott, R.B., Miggins, D.P., Budahn, J.R., Cooper, R.W., and Drenth, B.J. 2011. Geologic map of Big Bend National Park, Texas. US Department of the Interior, US Geological Survey.

Walton, A.H. 1992. Magnetostratigraphy and the age of the Bridgerian and Uintan faunas in the lower and middle members of the Devil's Graveyard Formation, Trans-Pecos Texas, p. 7487. In Prothero, D.R. and Berggren, W.A, (eds.), Eocene-Oligocene Climatic and Biotic Evolution. Princeton University Press, Princeton, N.J. https://doi.org/10.1515/9781400862924.74

Wang, Y. 1995. A new primitive Chalicothere (Perissodactyla, Mammalia) from the early Eocene of Hubei, China. Vertebrata PalAsiatica, 33:138-159.

Wilson, J. A. 1977a. Early tertiary vertebrate faunas Beg Bed Area Trans-Pecos Texas: Brontotheriidae. The Pearce-Sellards Series, 25:1-17.

Wilson, J. A. 1977b. Stratigraphic occurrence and correlation of early Tertiary vertebrate faunas, Trans-Pecos Texas. Part 1: Vieja Area. Texas Memorial Museum Bulletin, 25:1-42. 
Wilson, J.A. 1986. Stratigraphic Occurrence and Correlation of Early Tertiary Vertebrate Faunas, Trans-Pecos Texas: Agua Fria-Green Valley Areas. Journal of Vertebrate Paleontology, 6:350-373. https://doi.org/10.1080/02724634.1986.10011630

Wilson, J.A. and Stevens, M.S. 1986. Fossil vertebrates from the latest Eocene, Skyline channels, Trans-Pecos Texas. University of Wyoming Contributions to Geology Special Paper, 3:221-235. https://doi.org/10.2113/gsrocky.24.special_paper_3.221

Wood, H.E. 1938. Causal factors in shortening tooth series with age. Journal of Dental Research, 17: 1-13. https://doi.org/10.1177/00220345380170010101 


\section{APPENDICES}

\section{APPENDIX 1}

TABLE 1. Phylogentic character data in a .NEX file available for download in a zipped file.

\section{APPENDIX 2. \\ RESULTS OF EXPANDED PHYLOGENETIC ANALYSIS RESULTS FOR BRONTOTHERIIDAE}

Like earlier equally weighted parsimony analyses of Brontheriidae, the analysis produces excessive numbers of most parsimonious trees (MPTs) (tree length $=353 ; \mathrm{Cl}=0.4249 ; \mathrm{RI}=0.8096$ ) and poor resolution in the strict concensus (Figure A1), due to the unstable positions of fragmentary wildcard taxa, Nanotitanops shanghuanensis, Brachydiastematherium transylvanicum, and Notiotitanops mississippiensis (Mihlbachler 2007; 2008; 2009; Mihlbachler and Samuels 2016). Parsimony analysis in PAUP was stopped after discovery of 1,000,000 MPTs. A posteriori removal of these taxa and Maobrontops paganus Averianov et al. 2018, reveals numerous additional strictly supported relationships (Figure A2). Implied weighting searches performed in TNT discovered fewer MPTs. Searches where $k=3$ and $k=5$ produced 1485 MPTs and searches where $\mathrm{k}=6$ and $\mathrm{k}=7$ produced 120 MPTs and the most highly resolved strict consensus (Figure A3). A posteriori removal of one wildcard taxon, Nanotitanops shanghuangensis revealed additional strictly supported relationships among basal members of subtribe Brontotheriina (the clade consisting of brontotheres with frontonasal horns) (Figure A4). 


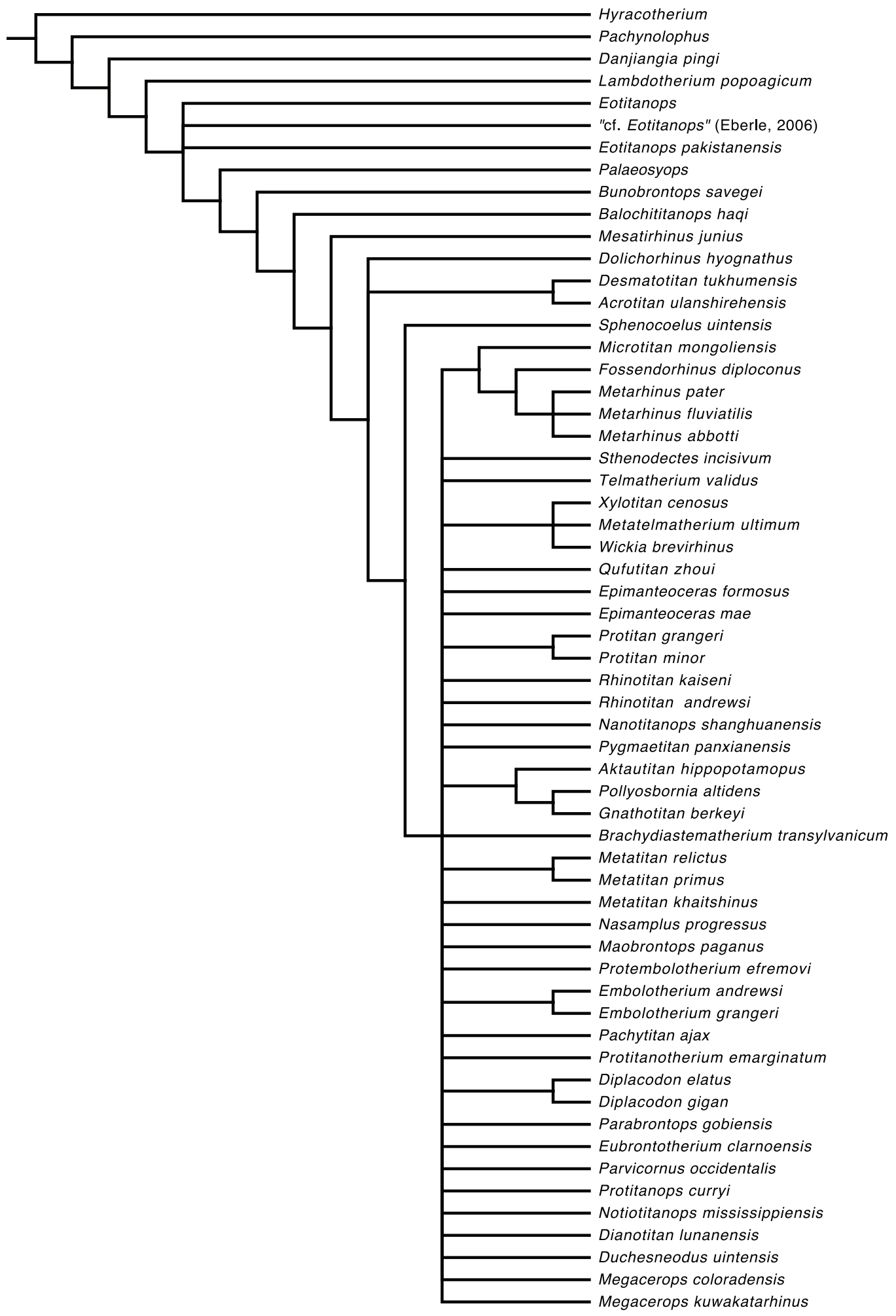

FIGURE A1. Strict consensus tree for Brontotheriidae based on a parsimony search with equally weighted characters. 


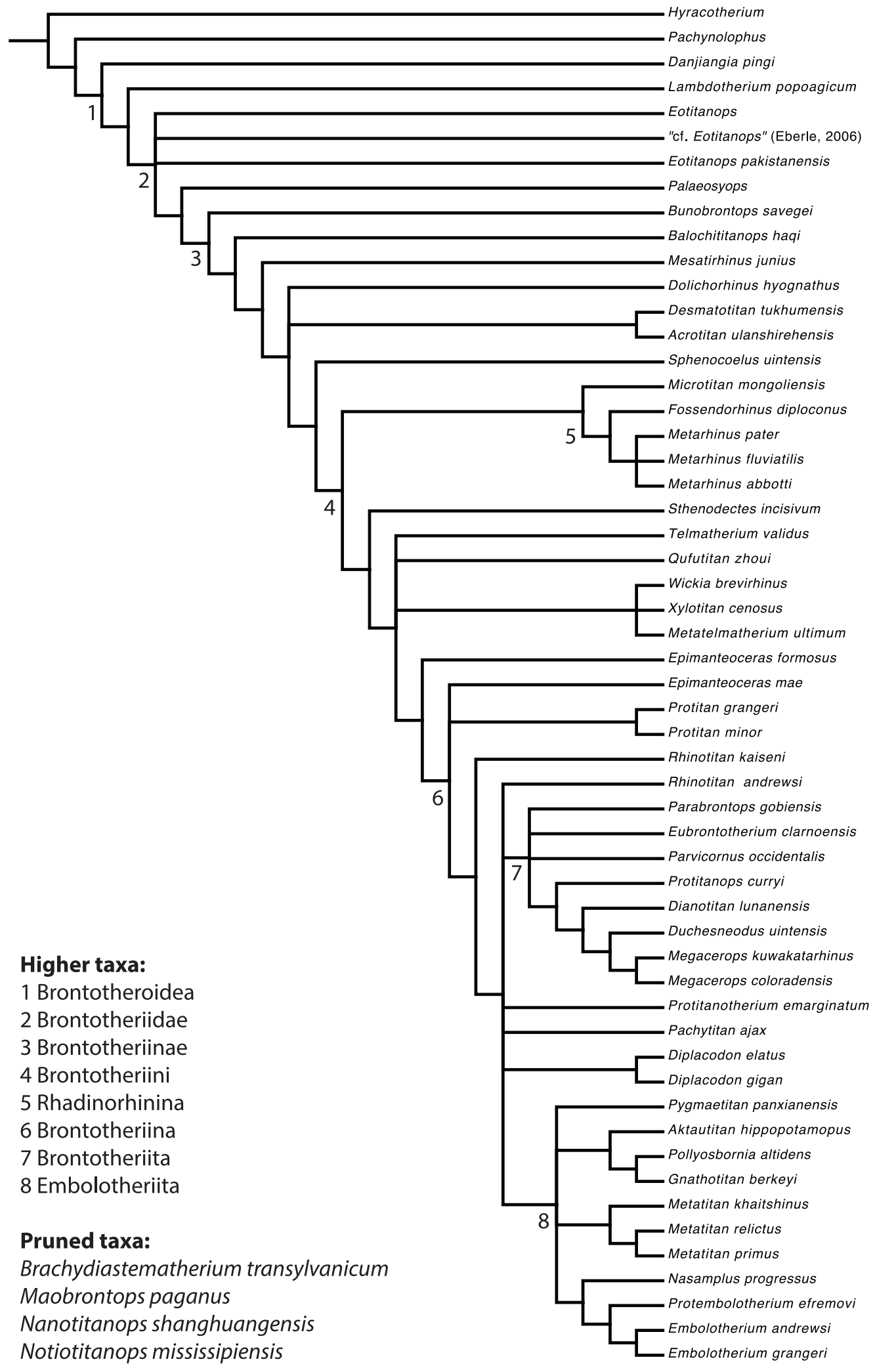

FIGURE A2. Reduced strict consensus tree for Brontotheriidae based on a parsimony search with equally weighted characters with wildcard taxa pruned a posteriori. 


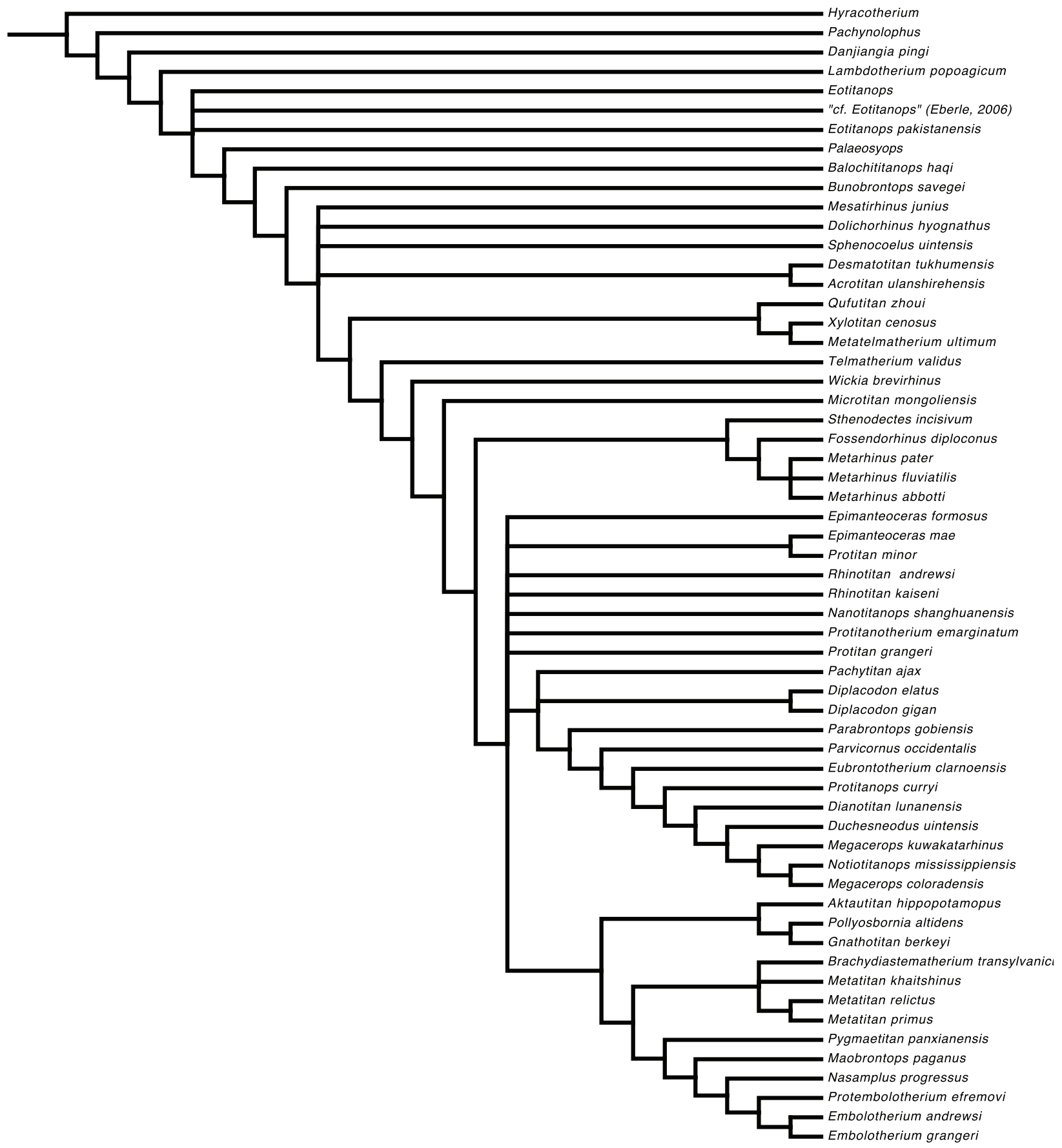

FIGURE A3. Strict consensus tree for Brontotheriidae based on a parsimony search with implied weighting $(\mathrm{k}=7)$. 


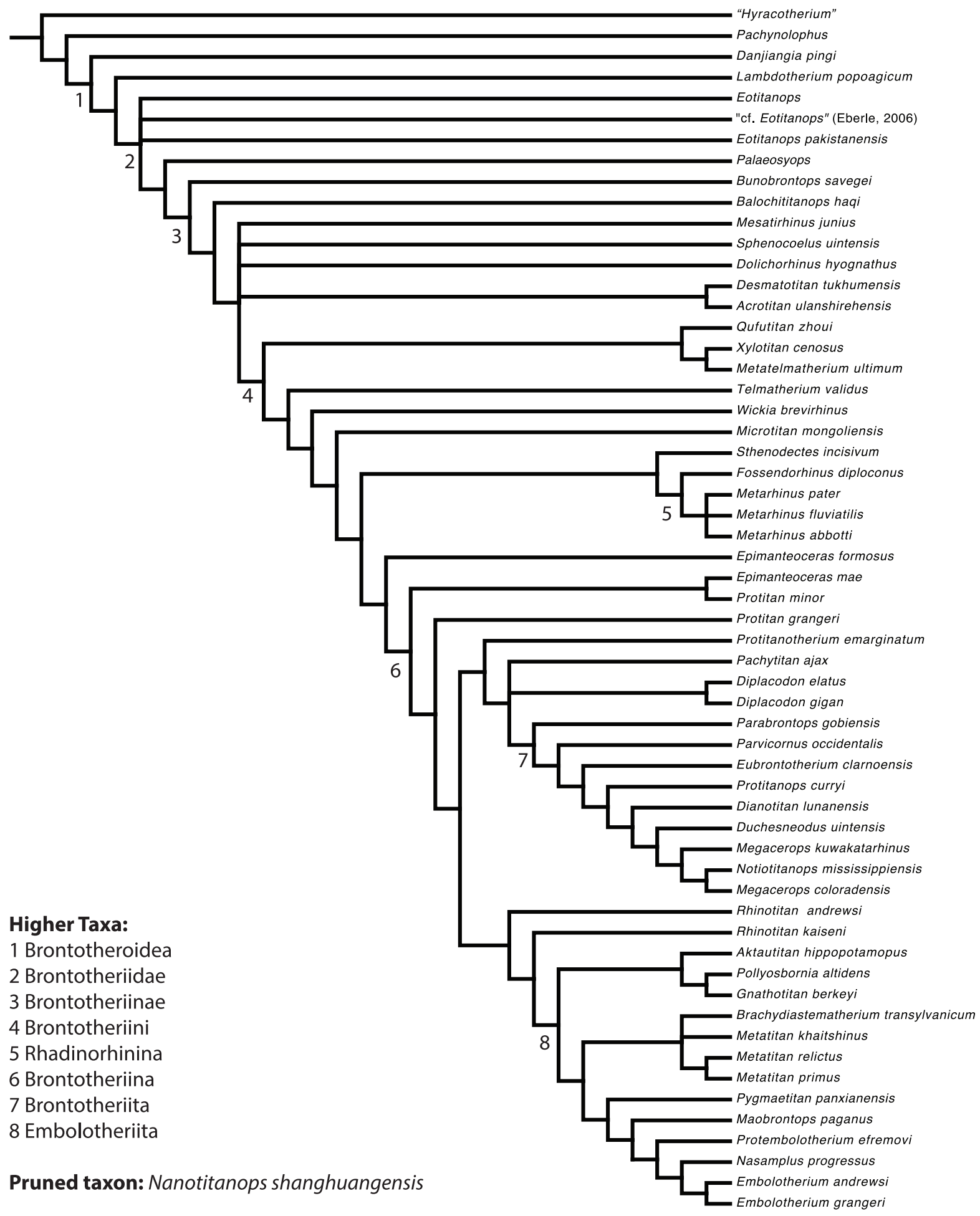

FIGURE A4. Reduced strict consensus tree for Brontotheriidae based on a parsimony search with implied weighting $(\mathrm{k}=7)$ with wildcard taxa pruned a posteriori. 


\section{APPENDIX 3}

TABLE 1A. Measurements (in $\mathrm{mm}$ ) of skulls and upper dentitions included in this study. Abbreviations are explained in Table $3 \mathrm{~A}$. Values preceded by $\sim$ are approximations due to distortion or incompleteness. Approximations were not used in generating any of the summary statistics provided in the paper.

\begin{tabular}{|c|c|c|c|c|c|c|c|c|c|c|c|c|c|c|c|c|}
\hline species & 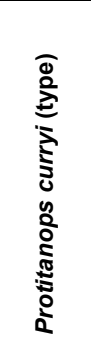 & 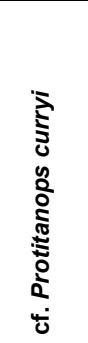 & 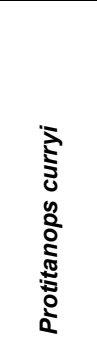 & 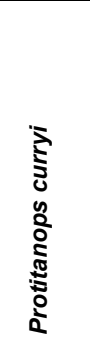 & 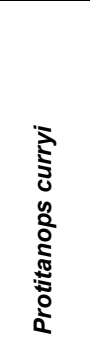 & 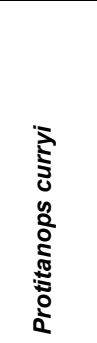 & 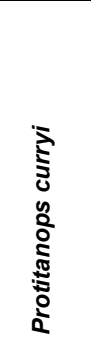 & 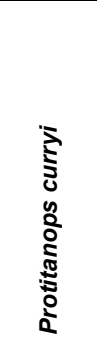 & 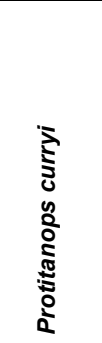 & 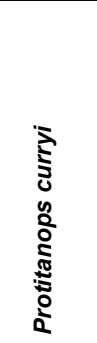 & 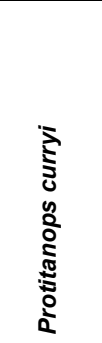 & 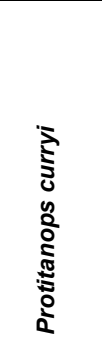 & 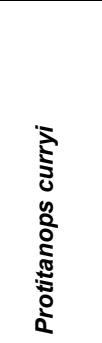 & 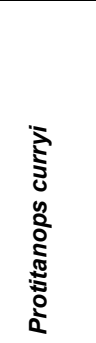 & 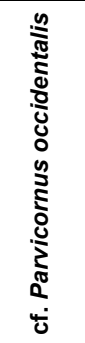 & 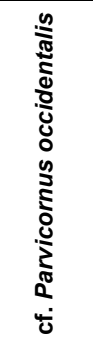 \\
\hline & & & $\begin{array}{c}\text { FMNH } \\
\text { PM }\end{array}$ & FMNH & $\begin{array}{c}\text { FMNH } \\
\text { PM }\end{array}$ & $\begin{array}{l}\text { FMNH } \\
\text { PM }\end{array}$ & FMNH & FMNH & $\begin{array}{l}\text { TMM } \\
\text { T0932. }\end{array}$ & & TMM & TMM & TMM & $\begin{array}{l}\text { TMM } \\
\text { T1916- }\end{array}$ & $\begin{array}{r}\text { TMM } \\
\text { (1580. }\end{array}$ & $\begin{array}{l}\text { TMM } \\
\text {. }\end{array}$ \\
\hline $\begin{array}{c}\text { collection } \\
\text { number }\end{array}$ & $\begin{array}{c}\text { CIT } \\
1854\end{array}$ & $\begin{array}{c}\text { CIT } \\
2007\end{array}$ & $\begin{array}{l}\text { PM } \\
137\end{array}$ & $\begin{array}{l}\text { PM } \\
138\end{array}$ & $\begin{array}{l}\text { PM } \\
139\end{array}$ & $\begin{array}{l}\text { PM } \\
157\end{array}$ & $\begin{array}{l}\text { PM } \\
205\end{array}$ & $\begin{array}{l}\text { PM } \\
398\end{array}$ & $\begin{array}{c}40932- \\
1\end{array}$ & $\begin{array}{l}\text { IGM } \\
65-29\end{array}$ & $\begin{array}{c}41916- \\
14\end{array}$ & $\begin{array}{c}-41916-< \\
19\end{array}$ & $\begin{array}{c}-41916-4 \\
6\end{array}$ & $\begin{array}{c}41916-4 \\
8\end{array}$ & $\begin{array}{c}41580 \\
30\end{array}$ & $\begin{array}{c}41853- \\
17\end{array}$ \\
\hline I1L & & & & & 8.62 & & & & & & & & & & & 8.05 \\
\hline I1W & & & & & 9.97 & & & & & & & & & & & 9.77 \\
\hline I2L & 6.37 & & & & 7.64 & & & & & & & & & & 7.74 & 15.28 \\
\hline $12 \mathrm{~W}$ & 8.1 & & & & 10.34 & & & & & & & & & & 9.48 & 11.74 \\
\hline I3L & 7.57 & & & & & & & & & & & & 9 & & 8.63 & \\
\hline I3W & 8.88 & & & & & & & & & & & & 9.49 & & 9.81 & \\
\hline$C L$ & 23.24 & & & & 25.35 & $\sim 31$ & & 29.66 & & & & & 24.4 & & 17 & 15.76 \\
\hline P1L & 18.38 & & & & & 17.81 & & & & & 21.8 & & 23.29 & & & 16 \\
\hline P1W & & & & & & 18.06 & & & & & & & 20.43 & & & 11.66 \\
\hline $\mathrm{P} 2 \mathrm{~L}$ & 26.12 & & 24.17 & & & 27.15 & & 24.92 & 30.77 & & & 28.18 & 30.94 & & & 19.98 \\
\hline P2W & 28.94 & & 31.07 & & & 34.76 & & & 34.98 & 30.99 & & 32.34 & 34.49 & & & 23.75 \\
\hline P3L & 28.66 & 37.02 & 31.92 & & 29.67 & 33.61 & & 30.75 & 34.39 & 30.22 & & 37.29 & 36.63 & & & 27.89 \\
\hline P3W & 37.69 & 45.87 & 39.89 & & 35.34 & 43.71 & & 45.01 & 43.73 & 37.99 & & 42.82 & 41.1 & & & 31.05 \\
\hline P4L & 32.27 & 49.13 & $\sim 31$ & & 39.43 & 43.17 & & 42.62 & 40.57 & 34.13 & & 39.9 & 40.31 & & & 31.58 \\
\hline P4W & 45.46 & 55.73 & 49.7 & & 40.69 & 55.98 & & 53.92 & 53.25 & 43.37 & & 51.94 & 50.79 & & & 38.2 \\
\hline M1L & 48.93 & & & & & & & 52.08 & & 47.44 & & 64.94 & 63.59 & & & 47.87 \\
\hline M1W & 50.33 & 66.35 & & & & & & 57.47 & & 49.31 & & 60.8 & 57.37 & & & 44.28 \\
\hline M2L & 64.87 & 82.54 & 68 & & & 69.55 & & 69.1 & & 70.59 & & 74.86 & 78.87 & & & 60.09 \\
\hline M2W & 64.17 & 68.61 & 66.26 & & & 71.62 & & 72.26 & & 60.14 & & 70.64 & 70.91 & & & 54.81 \\
\hline M3L & 75.45 & & 76.66 & & 81.74 & $\sim 71$ & & 74.58 & & 72.64 & & 77.29 & 81.1 & & & 64.77 \\
\hline M3W & 68.99 & & 70.51 & & 73.92 & 77.27 & 63.54 & 68.04 & & 65.24 & & 73.45 & 71.97 & & & 57.41 \\
\hline P2-P4 & 83.81 & & 90.73 & & & 101.99 & & 104.19 & 103.92 & & & 95 & 104.34 & & & 76.19 \\
\hline M1-M3 & 182 & & $\sim 180$ & & & 200 & $\sim 165$ & 180 & & 179.98 & & 192.39 & 225 & & & 170 \\
\hline P2-M3 & 267 & & $\sim 266$ & $\sim 260$ & & 295 & & 285 & & $\sim 264$ & & 265.61 & 298.7 & & & 236.1 \\
\hline DP3L & & & & & & & & & & & & & & 54.82 & & \\
\hline DP31 & & & & & & & & & & & & & & 47.12 & & \\
\hline VL & 688 & & 650 & & 698 & 660 & & $\sim 650$ & & & & & 642 & & & \\
\hline MVL & 632 & & 600 & & & 615 & & & & & & & 600 & & & \\
\hline
\end{tabular}




\begin{tabular}{|c|c|c|c|c|c|c|c|c|c|c|c|c|c|c|c|c|}
\hline species & 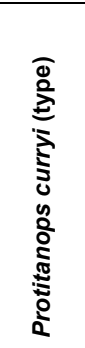 & 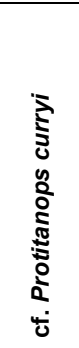 & 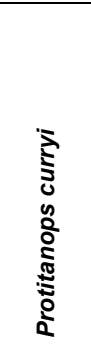 & 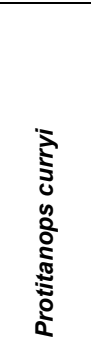 & 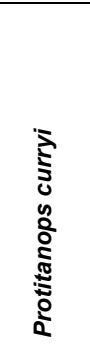 & 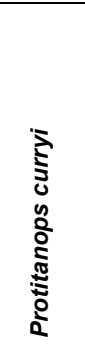 & 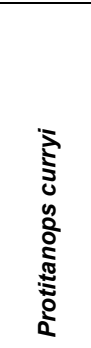 & 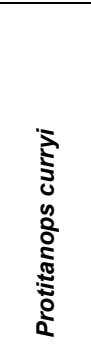 & 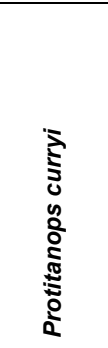 & 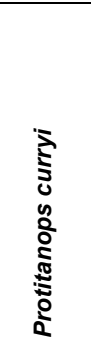 & 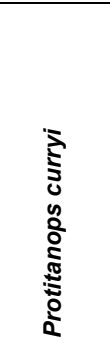 & 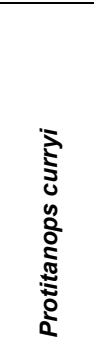 & 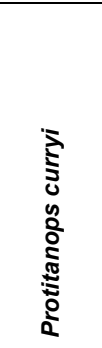 & 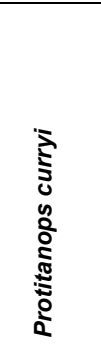 & 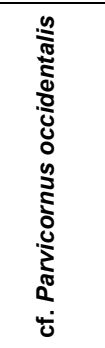 & 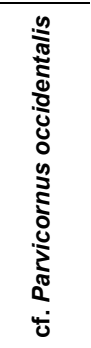 \\
\hline collection & CIT & CIT & $\begin{array}{c}\text { FMNH } \\
\text { PM }\end{array}$ & $\begin{array}{c}\text { FMNH } \\
\text { PM }\end{array}$ & $\begin{array}{c}\text { FMNH } \\
\text { PM }\end{array}$ & $\begin{array}{c}\text { FMNH } \\
\text { PM }\end{array}$ & $\begin{array}{l}\text { FMNH } \\
\text { PM }\end{array}$ & $\begin{array}{c}\text { FMNH } \\
\text { PM }\end{array}$ & $\begin{array}{l}\text { TMM } \\
40932-\end{array}$ & IGM & $\begin{array}{c}\text { TMM } \\
41916-4\end{array}$ & $\begin{array}{r}\text { TMM } \\
-41916-\end{array}$ & $\begin{array}{r}\text { TMM } \\
-41916-\end{array}$ & $\begin{array}{c}\text { TMM } \\
41916-4\end{array}$ & $\begin{array}{c}\text { TMM } \\
41580-4\end{array}$ & $\begin{array}{c}\text { TMM } \\
41853-\end{array}$ \\
\hline number & 1854 & 2007 & 137 & 138 & 139 & 157 & 205 & 398 & 1 & $65-29$ & 14 & 19 & 6 & 8 & 30 & 17 \\
\hline SW & 490 & & 487 & 600 & 540 & 510 & 370 & & $\sim 335$ & $\begin{array}{c}215 x \\
2\end{array}$ & & & & & & \\
\hline $\mathrm{HL}$ & $\begin{array}{c}133.9 \\
9\end{array}$ & & $\sim 100$ & & 140 & 80 & & & 90 & & & & & & & \\
\hline $\mathrm{HC}$ & 277 & & 220 & 240 & 300 & 260 & & & 220 & & & & & & & \\
\hline ZA & 87.82 & & 96.59 & 98.18 & 86.28 & 90.8 & 40.3 & & & 78.7 & & & 62.39 & & & \\
\hline
\end{tabular}


TABLE 2A. Measurements (in $\mathrm{mm}$ ) of mandibles and lower dentitions included in this study. Abbreviations are explained in Table 3A. Values preceded by $\sim$ are approximations due to distortion or incompleteness. Approximations were not used in generating any of the summary statistics provided in the paper.

\begin{tabular}{|c|c|c|c|c|c|c|c|c|c|c|c|}
\hline $\begin{array}{l}\text { species } \\
\text { collection }\end{array}$ & 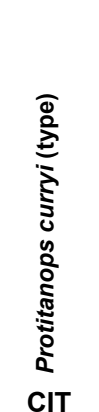 & 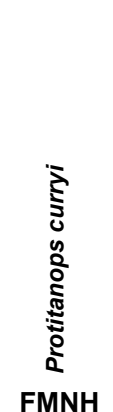 & 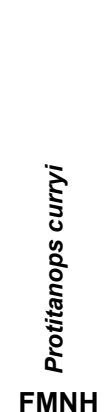 & 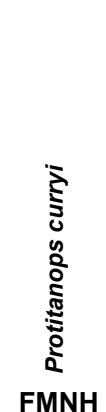 & 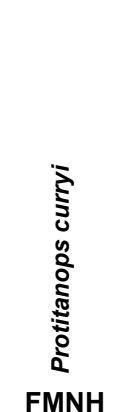 & 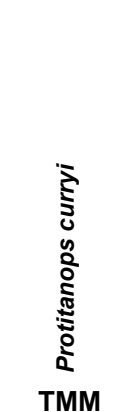 & 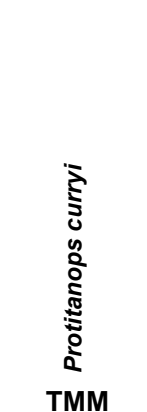 & 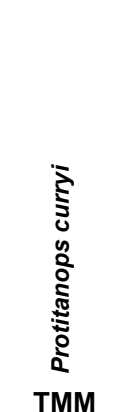 & 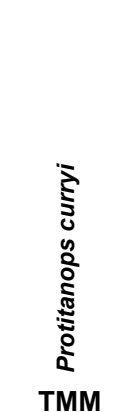 & 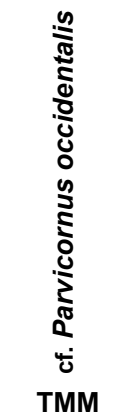 & 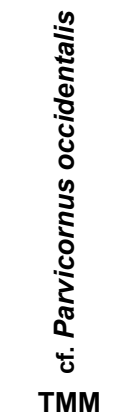 \\
\hline $\begin{array}{c}\text { collection } \\
\text { number }\end{array}$ & $\begin{array}{c}\text { CIT } \\
1854\end{array}$ & $\begin{array}{l}\text { FMNH } \\
\text { PM } 168\end{array}$ & $\begin{array}{l}\text { FMNH } \\
\text { PM } 399\end{array}$ & $\begin{array}{l}\text { FMNH } \\
\text { PM } 401\end{array}$ & $\begin{array}{c}\text { FMNH } \\
\text { PM } 402\end{array}$ & $\begin{array}{c}\text { TMM } \\
40840-38\end{array}$ & $\begin{array}{c}\text { TMM } \\
41916-14\end{array}$ & $\begin{array}{c}\text { TMM } \\
41916-8\end{array}$ & $\begin{array}{c}\text { TMM } \\
45805-1\end{array}$ & $\begin{array}{c}\text { TMM } \\
41715-6\end{array}$ & $\begin{array}{l}\text { TMM } \\
42254-2\end{array}$ \\
\hline i1L & & & & 7.74 & & & & & 7.37 & & \\
\hline $\mathrm{i} 1 \mathrm{~W}$ & & & & 11.06 & & & & & 9.86 & & \\
\hline $\mathrm{i} 2 \mathrm{~L}$ & & & & 11.8 & & & & 9.88 & 13.21 & & \\
\hline $\mathrm{i} 2 \mathrm{~W}$ & & & & 16 & & & & 11.87 & 15.18 & & \\
\hline i3L & & & & 7.89 & & & & & 8.58 & & \\
\hline i3W & & & & 10.93 & & & & & 11.44 & & \\
\hline $\mathrm{cL}$ & & & 35.59 & & & 19.01 & & & 28.16 & & \\
\hline $\mathrm{p} 1 \mathrm{~L}$ & & & 14.62 & & & & 17.53 & 15.91 & 13.54 & & \\
\hline $\mathrm{p} 1 \mathrm{~W}$ & & & 11.48 & & & 14.89 & & 11.15 & 9.29 & & \\
\hline p2L & & & 25.1 & & & & & & 25.79 & 9.84 & 20.84 \\
\hline $\mathrm{p} 2 \mathrm{~W}$ & & & 16.4 & & & & & & 15.94 & & 12.11 \\
\hline p3L & & & 32.16 & & & & & & 27.96 & 24.7 & 22.05 \\
\hline p3W & & & 23.44 & & & & & & 20.43 & & 14.7 \\
\hline $\mathrm{p} 4 \mathrm{~L}$ & & 36.45 & 36.18 & & & & & & 36.13 & 27.69 & 26.93 \\
\hline $\mathrm{p} 4 \mathrm{~W}$ & & & & & & & & & 25.51 & 20.37 & 18.67 \\
\hline $\mathrm{m} 1 \mathrm{~L}$ & 44.6 & 48.03 & 52.42 & 52.15 & & & & & 42.87 & 36.52 & 36.61 \\
\hline $\mathrm{m} 1 \mathrm{~W}$ & & & 31.75 & & & & & & 30.62 & 24.29 & 20.97 \\
\hline m2L & 56.67 & 63.02 & 68.09 & & & 58.49 & & & 62.49 & 49.77 & 48.55 \\
\hline $\mathrm{m} 2 \mathrm{~W}$ & & 39.27 & 40.47 & & & 33.04 & & & 37.72 & 30.17 & 24.6 \\
\hline m3L & 88.78 & 92.72 & 103.64 & & & 81 & & & & 74.82 & \\
\hline $\mathrm{m} 3 \mathrm{~W}$ & 35.41 & 41.22 & 37.86 & & & 33.91 & & & & 27.72 & 26.08 \\
\hline p2-p4 & 68.38 & & 91.98 & & & 88.79 & & & 89.25 & & 68.75 \\
\hline m1-m3 & 190 & 200 & 220 & $\sim 200$ & 240 & $\sim 185$ & & & & 160 & \\
\hline p2-m3 & 252 & & 310 & $\sim 300$ & $\sim 305$ & 272.34 & & & & & \\
\hline dp2L & & & & & & & 33.76 & 33.51 & & & \\
\hline $\mathrm{dp} 2 \mathrm{~W}$ & & & & & & & & 16.72 & & & \\
\hline dp3L & & & & & & & 38.24 & 38.94 & & & \\
\hline dp3W & & & & & & & & 20.87 & & & \\
\hline $\mathrm{dp} 4 \mathrm{~L}$ & & & & & & & 45.96 & 48.15 & & & \\
\hline $\mathrm{dp} 4 \mathrm{~W}$ & & & & & & & & 25.43 & & & \\
\hline
\end{tabular}


MihlbachleR \& PRothero: Texas BRontotheriIdAe

TABLE 3A. Abbreviations of measurements in Tables 1A and 2A.

\begin{tabular}{cl}
\hline Abbreviation & \multicolumn{1}{c}{ Measurement } \\
\hline $\mathrm{L}$ & mesiodistal length \\
$\mathrm{W}$ & transverse width \\
$\mathrm{VL}$ & ventral skull length \\
$\mathrm{MVL}$ & modified skull length (P2-occipital condyles) \\
$\mathrm{SW}$ & maximum transverse width of skull \\
$\mathrm{HL}$ & horn proximodistal length \\
$\mathrm{HC}$ & horn circumference at proximal base \\
ZA & maximum transverse thickness of zygomatic arch \\
\hline
\end{tabular}

